\title{
A compilation of global bio-optical in situ data for ocean-colour satellite applications
}

\author{
André Valente ${ }^{1}$, Shubha Sathyendranath ${ }^{2}$, Vanda Brotas ${ }^{1}$, Steve Groom $^{2}$, Michael Grant ${ }^{2}$, \\ Malcolm Taberner ${ }^{3}$, David Antoine ${ }^{4,5}$, Robert Arnone ${ }^{6}$, William M. Balch ${ }^{7}$, Kathryn Barker ${ }^{8}$, \\ Ray Barlow $^{9}$, Simon Bélanger ${ }^{10}$, Jean-François Berthon ${ }^{11}$, Şükrü Beşiktepe ${ }^{12}$, Vittorio Brando ${ }^{13,14}$, \\ Elisabetta Canuti ${ }^{11}$, Francisco Chavez ${ }^{15}$, Hervé Claustre ${ }^{16}$, Richard Crout $^{17}$, Robert Frouin ${ }^{18}$, \\ Carlos García-Soto ${ }^{19,20}$, Stuart W. Gibb ${ }^{21}$, Richard Gould ${ }^{17}$, Stanford Hooker ${ }^{22}$, Mati Kahru ${ }^{18}$, \\ Holger Klein ${ }^{23}$, Susanne Kratzer ${ }^{24}$, Hubert Loisel ${ }^{25}$, David McKee ${ }^{26}$, Brian G. Mitchell ${ }^{18}$, \\ Tiffany Moisan $^{27}$, Frank Muller-Karger ${ }^{28}$, Leonie O'Dowd ${ }^{29}$, Michael Ondrusek $^{30}$, Alex J. Poulton ${ }^{31}$, \\ Michel Repecaud ${ }^{32}$, Timothy Smyth ${ }^{2}$, Heidi M. Sosik ${ }^{33}$, Michael Twardowski ${ }^{34}$, Kenneth Voss ${ }^{35}$, \\ Jeremy Werdell $^{22}$, Marcel Wernand ${ }^{36}$, and Giuseppe Zibordi ${ }^{11}$ \\ ${ }^{1}$ Marine and Environmental Sciences Centre (MARE), University of Lisbon, Lisbon, Portugal \\ ${ }^{2}$ Plymouth Marine Laboratory, Plymouth, PL1 3DH, UK \\ ${ }^{3}$ EUMETSAT, Eumetsat-Allee 1, 64295 Darmstadt, Germany \\ ${ }^{4}$ Sorbonne Universités, UPMC Univ. Paris 06, CNRS, Laboratoire d'Océanographie de Villefranche, \\ Villefranche-sur-mer, 06238, France \\ ${ }^{5}$ Remote Sensing and Satellite Research Group, Department of Physics, Astronomy and Medical Radiation \\ Sciences, Curtin University, Perth, WA 6845, Australia \\ ${ }^{6}$ University of Southern Mississippi, Stennis Space Center, Kiln, MS, USA \\ ${ }^{7}$ Bigelow Laboratory for Ocean Sciences, East Boothbay, ME, USA \\ ${ }^{8}$ ARGANS Ltd, Plymouth, UK \\ ${ }^{9}$ Bayworld Centre for Research and Education, Cape Town, South Africa \\ ${ }^{10}$ Département de biologie, chimie et géographie, Université du Québec à Rimouski, \\ Rimouski (Québec), Canada \\ ${ }^{11}$ European Commission, Joint Research Centre, Ispra, Italy \\ ${ }^{12}$ Institute of Marine Science and Technology, Dokuz Eylul University, Izmir, Turkey \\ ${ }^{13}$ CSIRO Oceans and Atmosphere, Canberra, Australia \\ ${ }^{14}$ CNR IREA, Milan, Italy \\ ${ }^{15}$ Monterey Bay Aquarium Research Institute, Moss Landing, CA, USA \\ ${ }^{16}$ Laboratoire d'Océanographie de Villefranche (LOV), Sorbonne Universités, UPMC Univ Paris 06, \\ INSU-CNRS, 181 Chemin du Lazaret, 06230 Villefranche-sur-Mer, France \\ ${ }^{17}$ Naval Research Laboratory, Stennis Space Center, Kiln, MS, USA \\ ${ }^{18}$ Scripps Institution of Oceanography, University of California, San Diego, CA, USA \\ ${ }^{19}$ Spanish Institute of Oceanography (IEO), Corazón de María 8, 28002 Madrid, Spain \\ ${ }^{20}$ Plentziako Itsas Estazioa/Euskal Herriko Unibetsitatea (PIE/EHU), Areatza z/g, 48620 Plentzia, Spain \\ ${ }^{21}$ Environmental Research Institute, North Highland College, University of the Highlands and Islands, \\ Thurso, Scotland, UK \\ ${ }^{22}$ NASA Goddard Space Flight Center, Greenbelt, Maryland, USA \\ ${ }^{23}$ Operational Oceanography Group, Federal Maritime and Hydrographic Agency, Hamburg, Germany \\ ${ }^{24}$ Department of Ecology, Environment and Plant Sciences, Frescati Backe, Stockholm University, \\ 10691 Stockholm, Sweden \\ ${ }^{25}$ Laboratoire d'Océanologie et de Géosciences, Université du Littoral - Côte d'Opale, \\ Maison de la Recherche en Environnement Naturel, Wimereux, France \\ ${ }^{26}$ Physics Department, University of Strathclyde, Glasgow G4 0NG, Scotland, UK
}




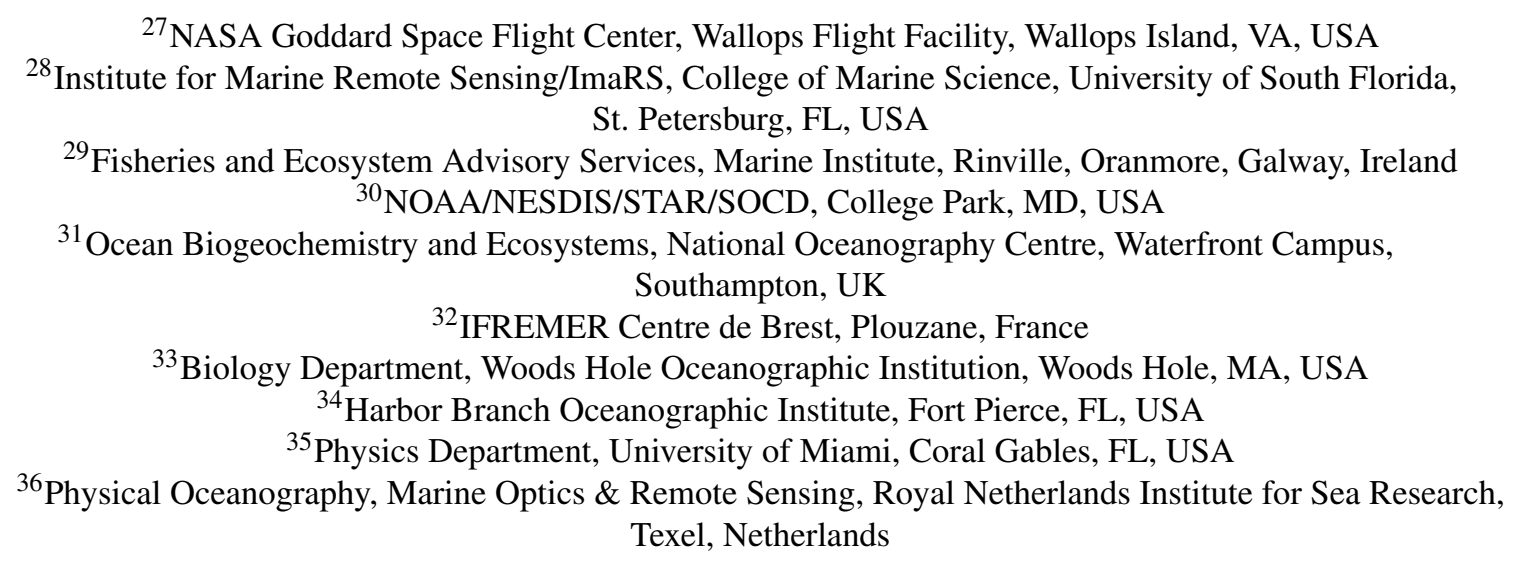

Correspondence to: André Valente (adovalente@fc.ul.pt)

Received: 11 November 2015 - Published in Earth Syst. Sci. Data Discuss.: 19 January 2016

Revised: 18 May 2016 - Accepted: 19 May 2016 - Published: 3 June 2016

\begin{abstract}
A compiled set of in situ data is important to evaluate the quality of ocean-colour satellite-data records. Here we describe the data compiled for the validation of the ocean-colour products from the ESA Ocean Colour Climate Change Initiative (OC-CCI). The data were acquired from several sources (MOBY, BOUSSOLE, AERONET-OC, SeaBASS, NOMAD, MERMAID, AMT, ICES, HOT, GeP\&CO), span between 1997 and 2012, and have a global distribution. Observations of the following variables were compiled: spectral remote-sensing reflectances, concentrations of chlorophyll $a$, spectral inherent optical properties and spectral diffuse attenuation coefficients. The data were from multi-project archives acquired via the open internet services or from individual projects, acquired directly from data providers. Methodologies were implemented for homogenisation, quality control and merging of all data. No changes were made to the original data, other than averaging of observations that were close in time and space, elimination of some points after quality control and conversion to a standard format. The final result is a merged table designed for validation of satellite-derived ocean-colour products and available in text format. Metadata of each in situ measurement (original source, cruise or experiment, principal investigator) were preserved throughout the work and made available in the final table. Using all the data in a validation exercise increases the number of matchups and enhances the representativeness of different marine regimes. By making available the metadata, it is also possible to analyse each set of data separately. The compiled data are available at doi:10.1594/PANGAEA.854832 (Valente et al., 2015).
\end{abstract}

\section{Introduction}

Currently, there are several bio-optical in situ datasets worldwide suitable for validation of ocean-colour satellite data. While some are managed by the data producers, others are in international repositories with contributions from multiple scientists. Many have rigid quality controls and are built specifically for ocean-colour validation. The use of only one of these datasets would limit the number of data in validation exercises. It would therefore be useful to acquire and merge all these datasets into a single unified dataset to maximise the number of matchups available for validation and their distribution in time and space and consequently reduce the uncertainties in the validation exercise. However, merging several datasets together can be a complicated task. First, it is necessary to acquire and harmonise all datasets into a single standard format. Second, during the merging, the du- plicates between datasets have to be identified and removed. Third, the metadata should be propagated throughout the process and made available in the final merged product. Ideally, the compiled dataset would be made available as a simple text table, to facilitate ease of access and manipulation. In this work such unification of multiple datasets is presented. This was done for the validation of the ocean-colour products from the ESA Ocean Colour Climate Change Initiative (OC$\mathrm{CCI}$ ), but with the intent to serve the broad user community as well.

A merged dataset is not without drawbacks: it is likely to be large and so not always easy to manipulate; because the merging is done on pre-existing, processed databases, one does not have full command of the whole processing chain; and the dataset would be a compilation of observations collected by several investigators using different instruments, sampling methods and protocols, which might even- 
tually have been modified by the processing routines used by the repositories or archives. Nevertheless, to minimise these potential drawbacks, we have, for the most part, incorporated only datasets that have emerged from the long-term efforts of the ocean-colour and biological oceanographic communities to provide scientists with high-quality in situ data and implemented additional quality checks on the data to enhance confidence in the quality of the merged product.

In Sect. 2 the methodologies used to harmonise and integrate all data, as well as a description of individual datasets acquired, are provided. In Sect. 3 the geographic distribution and other characteristics of the final merged dataset are shown. Section 4 provides an overview of the data.

\section{Data and methods}

\subsection{Preprocessing and merging}

The compiled global set of bio-optical in situ data described in this work has an emphasis, though not exclusively, on open-ocean data from all geographic regions. It is comprised of the following variables: remote-sensing reflectance (rrs), chlorophyll $a$ concentration (chla), algal pigment absorption coefficient (aph), detrital and coloured dissolved organic matter absorption coefficient (adg), particle backscattering coefficient (bbp) and diffuse attenuation coefficient for downward irradiance $(\mathrm{kd})$. A similar effort of compiling biooptical in situ data from different sources has been recently published by Nechad et al. (2015). Given their focus on selected coastal regions, most of the data presented here are not part of their compilation. The variables rrs, aph, adg, bbp and $\mathrm{kd}$ are spectrally dependent, and this dependence is hereafter implied. The data were compiled from 10 sources of in situ data (MOBY, BOUSSOLE, AERONET-OC, SeaBASS, NOMAD, MERMAID, AMT, ICES, HOT, GeP\&CO), each described in Sect. 2.2. The compiled in situ observations have a global distribution and cover the recent period of satellite ocean-colour data between 1997 and 2012. The listed variables were chosen as they are the operational satellite oceancolour products of the ESA OC-CCI project, which currently focuses on the use of three ocean-colour satellite platforms to create a time series of satellite data: the Medium Resolution Imaging Spectrometer (MERIS) of ESA, the Moderate Resolution Imaging Spectroradiometer (MODIS) of NASA, and the Sea-viewing Wide Field-of-view Sensor (SeaWiFS) of NASA, .

Rrs is a primary ocean-colour product routinely produced by several space agencies. It is defined as $\mathrm{rrs}=\mathrm{Lw} / \mathrm{Es}$, where Lw is the upward water-leaving radiance and Es is the total downward irradiance at sea level. Remote-sensing reflectance is related to irradiance reflectance $(\mathrm{Rw})$ approximately through $\mathrm{rrs}=\mathrm{Rw} / Q$, where $Q$ ranges from 3 to 5 in natural waters and is equal to $\pi$ for an isotropic (Lambertian) light field. Another quantity that is often required is the "normalised" water-leaving radiance (nLw) (Gordon and Clark, 1981), which is related to remote-sensing reflectance via $\mathrm{rrs}=\mathrm{nLw} / \mathrm{Fo}$, where Fo is the top-of-theatmosphere solar irradiance. If not directly available, remotesensing reflectance was calculated through the equations described above, depending on the format of the original data. The original data were acquired in an advanced form (e.g. time-averaged, extrapolated to surface) from six data sources particularly designed for ocean-colour validation (MOBY, BOUSSOLE, AERONET-OC, SeaBASS, NOMAD, MERMAID), therefore only requiring the conversion to a common format. In the processing made by the space agencies, the quantity rrs is normalised to a single Sun-viewing geometry (Sun at zenith and nadir viewing) taking in account the bidirectional effects as described in Morel and Gentili (1996) and Morel et al. (2002). Thus, for consistency with the satellite rrs product, only in situ rrs that included the latter normalisation was included in the compilation.

Chlorophyll $a$ concentration is the traditional measure for phytoplankton biomass and one of the most widely used satellite ocean-colour products (IOCCG, 2008). To validate satellite-derived chlorophyll $a$ concentration, two different variables were compiled: one of these represents chlorophyll $a$ measurements made through fluorometric or spectrophotometric methods, referred to hereafter as chla_fluor and the other is the chlorophyll concentration derived from HPLC (high-performance liquid chromatography) measurements, referred to hereafter as chla_hplc. The chlorophyll data were compiled from eight data sources: BOUSSOLE, SeaBASS, NOMAD, MERMAID, AMT, ICES, HOT and GeP\&CO. One requirement for chla_fluor measurements was that they were made using in vitro methods (i.e. based on extractions of chlorophyll $a$ ). Although this severely decreased the number of observations, since in situ fluorometry (e.g. fluorometers mounted on CTDs) is widely available in oceanographic databases, it was decided to exclude such data because of potential problems with the calibration of in situ fluorometers. The variable chla_hplc was calculated by summing all reported chlorophyll $a$ derivatives, including divinyl chlorophyll $a$, epimers, allomers and chlorophyllide $a$. The two chlorophyll variables are retained separately in the database to facilitate their use. HPLC measurements are considered of higher quality, but fluorometric measurements are more abundant. Thus one option for users is to use chla_fluor only when there are no chla_hplc measurements available. To be consistent with satellite-derived chlorophyll values, which are derived from the light emerging from the upper layer of the ocean, all chlorophyll observations found in the top $10 \mathrm{~m}$ (replicates at the same depth or measurements at multiple depths) were averaged if the coefficient of variation among observations was less than $50 \%$; otherwise they were discarded. The averages were then assigned to the surface. The depth of $10 \mathrm{~m}$ was chosen as a compromise between clear oligotrophic and turbid eutrophic waters. Other methods, such as chlorophyll depth averages using local attenuation conditions (Morel and Maritorena, 2001), require 
observations at multiple depths, which, given our decision to use only in vitro measurements, would have reduced considerably the final number of observations.

With regard to the inherent optical properties (aph, adg, bbp), if not already calculated and provided in the contributed datasets, they were computed from related variables that were available: particle absorption (ap), detrital absorption (ad), coloured dissolved organic matter (CDOM) absorption (ag) and total backscattering (bb). The following equations were used adg $=a d+a g, a p=a p h+a d$ and $\mathrm{bb}=\mathrm{bbp}+\mathrm{bbw}$. For the latter equation, the variable bbw was computed using bbw $=\mathrm{bw} / 2$, where $\mathrm{bw}$ is the scattering coefficient of seawater derived from Zhang et al. (2009). The diffuse attenuation coefficient for downward irradiance (kd) did not require any conversion and was compiled as originally acquired. Observations of inherent optical properties (surface values) and diffuse attenuation coefficient for downward irradiance, were acquired from three data sources particularly designed for ocean-colour validation (SeaBASS, NOMAD, MERMAID) and were thus already subject to the processing routines of these datasets.

The merged dataset was compiled from 10 sets of in situ data, which were obtained individually either from archives that incorporate data from multiple contributors (SeaBASS, NOMAD, MERMAID and ICES) or from particular measurement programs or projects (MOBY, BOUSSOLE, AERONET-OC, HOT, GeP\&CO, AMT) and were subsequently homogenised and merged. Data contributors are listed in Table 2. There were methodological differences between datasets. Therefore, after acquisition, and prior to any merging, each set of data was preprocessed for quality control and conversion to a common format. During this process, data were discarded if they had (1) unrealistic or missing date, time and geographic coordinate fields; (2) poor quality (e.g. original flags) or a method of observation that did not meet the criteria for the dataset (e.g. in situ fluorescence for chlorophyll concentration); and (3) spuriously high or low data. For the latter, the following limits were imposed: for chla_fluor and chla_hplc $[0.001-100] \mathrm{mg} \mathrm{m}^{-3}$; for $\mathrm{rrs}[0-0.15] \mathrm{sr}^{-1}$; for aph, adg and bbp [0.0001-10] $\mathrm{m}^{-1}$; for $\mathrm{kd}[\mathrm{aw}(\lambda)-10] \mathrm{m}^{-1}$, where aw is the pure water absorption coefficients derived from Pope and Fry (1997). Also during this stage, three metadata strings were attributed to each observation: dataset, subdataset and pi. The dataset contains the name of the original set of data, and can only be one of the following: "aoc", "boussole", "mermaid", "moby", "nomad", "seabass", "hot", "ices", "amt" or "gepco". The subdataset starts with the dataset identifier and is followed by additional information about the data, in the format $<$ dataset>_<cruise/station/site>) (e.g. seabass_car71). The pi contains the name of the principal investigator(s). An effort was made to homogenise the names of principal investigators from the different sets of data. These three metadata are the link to trace each observation to its origin and were propagated throughout the processing. Finally, this processing stage ended with each set of data being scanned for replicate variable data and replicate station data, which when found, were averaged if the coefficient of variation was less than $50 \%$; otherwise they were discarded. Replicates were defined as multiple observations of the same variable, with the same date, time, latitude, longitude and depth. Replicate station data were defined as multiple measurements of the same variable, with the same date, time, latitude and longitude. For the latter case, a search window of $5 \mathrm{~min}$ in time and $200 \mathrm{~m}$ in distance was given, to account for station drift. A small number of observations that were identified as replicates had different subdataset identifiers (i.e. a different cruise name). These observations were considered suspicious if the values were different and were discarded. If the values were the same, one of the observations was retained. This possibly originated from the same group of data being contributed to an archive by two different principal investigators.

Once each set of data was homogenised, all data were integrated into a unique table. This final merging focused on the removal of duplicates between the sets of data. Although some duplicates are known (e.g. MOBY, BOUSSOLE, AERONET-OC and NOMAD data are found in SeaBASS and MERMAID sets of data), others are unknown (e.g. how much of GeP\&CO, ICES, AMT, HOT is within NOMAD, SeaBASS and MERMAID). Therefore, duplicates were identified using the metadata (dataset and subdataset) when possible and temporal-spatial matches as an additional precaution. For temporal-spatial matches, several thresholds were used, but typically $5 \mathrm{~min}$ and $200 \mathrm{~m}$ were taken to be enough to identify most duplicated data, which reflected small differences in time, latitude and longitude, between the different sets of data. Larger thresholds were used in some cases as a cautionary procedure. This was the case when searching for NOMAD data in other datasets because NOMAD includes a few cases where merging of radiometric and pigment data was done with large spatialtemporal thresholds (Werdell and Bailey, 2005). With regard to all data, if duplicates were found, data from the NOMAD dataset were selected first, followed by data from individual projects (MOBY, BOUSSOLE, AERONET-OC, AMT, HOT and GeP\&CO) and finally for the remaining datasets (SeaBASS, MERMAID and ICES). This procedure was chosen to preserve the NOMAD dataset as a whole, since it is widely used in ocean-colour validation. After all data were free of duplicates, they were merged consecutively by variable in the final table. During this process, we also searched for rows (stations) that were separated from each other by time differences less than 5 min and horizontal spatial differences of less than $200 \mathrm{~m}$. When such rows were found, the observations in those rows were merged into a single row. The compiled merged data were compared with the original sets to certify that no errors occurred during the merging. As a final step, a water-column (station) depth was recorded for each observation, which was the closest water-column depth from the ETOPO1 global relief model (National Geophys- 
ical Data Center ETOPO1; Amante and Eakins, 2009). For observations where the closest water depth was above sea level (e.g. data collected very near the coast), it was given the value of zero.

Data processing thus included two major steps: preprocessing and merging. The first step was related to each set of contributing datasets in particular and aimed to identify problems and convert the data of interest to a standard format. The second step dealt with the integration of all data into one unique file and included the elimination of duplicated data between the individual sets of data acquired. In the next subsections a brief overview of each original set of data is provided.

\subsection{Preprocessing of each set of data}

\subsubsection{Marine Optical Buoy (MOBY)}

The Marine Optical Buoy (MOBY) is a fixed mooring system operated by the National Oceanic and Atmospheric Administration (NOAA) that provides a continuous time series of water-leaving radiance and surface irradiance in the visible region of the spectra from 1997 onwards. The site is located a few kilometres west of the Hawaiian island of Lāna' $i$ where the water depth is about $1200 \mathrm{~m}$. Since its deployment, MOBY measurements have been the primary basis for the on-orbit vicarious calibrations of the SeaWiFS and MODIS ocean-colour sensors. A full description of the MOBY system and processing is provided in Clark et al. (2003). Data are freely available for scientific use at the MOBY Gold directory. The products of interest are the Scientific Time Series files, which refer to MOBY data averaged over sensorspecific wavelengths and particular hours of the day (around 20:00-23:00 UTC). For this work, the satellite band-average products for SeaWiFS, MODIS AQUA and MERIS were compiled from the January 2005 reprocessing for the early data and from the latest reprocessing for data after 2011. The "inband" average subproduct was used, and to maintain the highest quality, only data determined from the upper two arms (Lw1) and flagged "good" quality were acquired. Data from the MOBY203 deployment were discarded due to the absence of surface irradiance data. The compiled variable was the remote-sensing reflectance, rrs, which was computed from the original water-leaving radiance $(\mathrm{Lw})$ and surface irradiance (Es). The water-leaving radiances were corrected for the bidirectional nature of the light field (Morel and Gentili, 1996; Morel et al., 2002) using the same look-up table and method as that used in the SeaWiFS Data Analysis System (SeaDAS) processing code. As mentioned before, the MOBY data compiled in this work are sensor-specific. Therefore, attention is necessary to use the correct MOBY data when validating a particular sensor. The way MOBY data are stored in the final merged table is consistent with the original wavelengths; however, these wavelengths can differ from what is sometimes expected to be the central wavelength of a given band and sensor. Irrespective of the wavelength where MOBY data are stored in the final table, for validation of bands 1-6 of SeaWiFS, MOBY data stored in the final merged table at 412, 443, 490, 510, 555 and $670 \mathrm{~nm}$, respectively, should be used. For validation of bands 1-6 of MODIS AQUA, MOBY data stored in the final merged table at 416, 442, 489, 530, 547 and $665 \mathrm{~nm}$, respectively, should be used. Finally, for validation of bands 1-7 of MERIS, MOBY data stored in the final merged table at $410.5,440.4,487.8,507.7,557.6,617.5$ and $662.4 \mathrm{~nm}$, respectively, are the appropriate data.

\subsubsection{BOUée pour l'acquiSition de Séries Optiques à Long termE (BOUSSOLE)}

The BOUée pour l'acquiSition de Séries Optiques à Long termE (BOUSSOLE) project started in 2001 with the objective of establishing a time series of bio-optical properties in oceanic waters to support the calibration and validation of ocean-colour satellite sensors (Antoine et al., 2006). The project is composed of a monthly cruise program and a permanent optics mooring (Antoine et al., 2008). The mooring collects radiometry and inherent optical properties (IOPs) in continuous mode every $15 \mathrm{~min}$ at two depths (4 and $9 \mathrm{~m}$ nominally). The monthly cruises are devoted to the mooring servicing, to the collection of vertical profiles of radiometry and IOPs, and to water sampling at 11 depths from the surface down to $200 \mathrm{~m}$, for subsequent analyses including phytoplankton pigments, particulate absorption, CDOM absorption and suspended particulate matter load. The BOUSSOLE mooring is in the western Mediterranean Sea at a water depth of $2400 \mathrm{~m}$. All pigment (2001-2012) and radiometric (2003-2012) data were provided by the principal investigator. The compiled variables were rrs and chla_hplc. Observations of the diffuse attenuation coefficient $(\mathrm{kd})$ were not included in the present compilation, as they were under internal quality revision at the time of data acquisition. Remote-sensing reflectance was computed from the original "fully normalised" water-leaving radiance (nLw_ex), which is the "normalised" water-leaving radiance (nLw previously described), with a correction for the bidirectional nature of the light field (Morel and Gentili, 1996; Morel et al., 2002). The solar irradiance (Fo) was computed from two available variables in the original set of data $-\mathrm{nLw}$ and $\mathrm{rrs}-$ using the equation $\mathrm{Fo}=\mathrm{nLw} / \mathrm{rrs}$. Only radiometric observations that meet the following criteria were used: (1) tilt of the buoy was less than $10^{\circ}$; (2) the buoy was not lowered by more than $2 \mathrm{~m}$ as compared to its nominal water line (to ensure the Es reference sensor is above water and exempt from sea spray); and (3) the solar irradiance was within $10 \%$ of its theoretical clear-sky value (determined from Gregg and Carder, 1990). The latter criterion was used to select clear skies only. An additional quality control was to remove observations that were $50 \%$ higher or lower than the daily average. This removed a small number of spikes in the time series. The final 
quality control step was to remove days where the standard deviation was more than half of the daily average. This was meant to identify days with high variability. Very few days $(N=2)$ were removed with this test. These quality control criteria were applied per wavelength, which resulted in some observations with an incomplete spectrum.

\subsubsection{AErosol RObotic NETwork-Ocean Color (AERONET-OC)}

The AErosol RObotic NETwork-Ocean Color (AERONETOC) is a component of AERONET, including sites where sun photometers operate with a modified measurement protocol leading to the determination of the fully normalised water-leaving radiance (Zibordi et al., 2006, 2009). The result of collaboration between the Joint Research Centre (JRC) and NASA, this component has been specifically developed for the validation of ocean-colour radiometric products. The strength of AERONET-OC is "the production of standardised measurements that are performed at different sites with identical measuring systems and protocols, calibrated using a single reference source and method, and processed with the same codes" (Zibordi et al., 2006, 2009). All high-quality data (level 2) were acquired from the project website for 11 sites: Abu_Al_Bukhoosh $\left(\sim 25^{\circ} \mathrm{N}, \sim 53^{\circ} \mathrm{E}\right)$, COVE_SEAPRISM $\left(\sim 36^{\circ} \mathrm{N}, \sim 75^{\circ} \mathrm{W}\right)$, Gloria $\left(\sim 44^{\circ} \mathrm{N}\right.$, $\left.\sim 29^{\circ} \mathrm{E}\right)$, Gustav_Dalen_Tower $\left(\sim 58^{\circ} \mathrm{N}, \sim 17^{\circ} \mathrm{E}\right)$, Helsinki Lighthouse $\left(\sim 59^{\circ} \mathrm{N}, \sim 24^{\circ} \mathrm{E}\right)$, LISCO $\left(\sim 40^{\circ} \mathrm{N}, \sim 73^{\circ} \mathrm{W}\right)$, Lucinda $\left(\sim 18^{\circ} \mathrm{S}, \sim 146^{\circ} \mathrm{E}\right)$, MVCO $\left(\sim 41^{\circ} \mathrm{N}, \sim 70^{\circ} \mathrm{W}\right)$, Palgrunden $\left(\sim 58^{\circ} \mathrm{N}, \sim 13^{\circ} \mathrm{E}\right)$, Venice $\left(\sim 45^{\circ} \mathrm{N}, \sim 12^{\circ} \mathrm{E}\right)$ and WaveCIS_Site_CSI_6 $\left(\sim 28^{\circ} \mathrm{N}, \sim 90^{\circ} \mathrm{W}\right)$. The compiled variable was rrs. Remote-sensing reflectance was computed from the original fully normalised water-leaving radiance (see Sect. 2.2.2 for definition). The solar irradiance ( $F o$ ), which is not part of the AERONET-OC data, was computed from the Thuillier (2003) solar spectrum irradiance by averaging Fo over a wavelength-centred $10 \mathrm{~nm}$ window. Data were compiled for the exact wavelengths of each record, which can change over time for a given site depending on the specific instrument deployed.

\subsubsection{SeaWiFS Bio-optical Archive and Storage System (SeaBASS)}

The SeaWiFS Bio-optical Archive and Storage System (SeaBASS) is one of the largest archives of in situ marine bio-optical data (Werdell et al., 2003). It is maintained by NASA's Ocean Biology Processing Group (OBPG) and includes measurements of optical properties, phytoplankton pigment concentrations, and other related oceanographic and atmospheric data. The SeaBASS database consists of in situ data from multiple contributors, collected using a variety of measurement instruments with consistent, community-vetted protocols, from several marine platforms such as fixed buoys, hand-held radiometers and profiling instruments. Quality control of the received data includes a rigorous series of protocols that range from file format verification to the inspection of the geophysical data values (Werdell et al., 2003). Radiometric data were acquired through the Validation search tool, which provided in situ data with matchups for particular ocean-colour sensors (Bailey and Werdell, 2006). The criteria in the search query were defined to have the minimal flag conditions in the satellite data in order to retrieve a greater number of matchups and therefore in situ data. Regarding phytoplankton pigment data, they were acquired through the Pigment search tool, which provides pigment data directly from the archives. As stated in the SeaBASS website (see Pigment tab at http://seabass.gsfc.nasa.gov/seabasscgi/ search.cgi), the Pigment search tool was originally designed to return only in vitro fluorometric measurements, which is consistent with our approach, but over time chlorophyll $a$ measurements made using other methods (e.g. in situ fluorometry) were included in the retrieved pigment data. In the pigment data used in this work, a large number of in situ fluorometric measurements from continuous underway instruments were identified and discarded. These data were firstly identified from cruises with more than 50 observations per day and then re-checked on the SeaBASS website to confirm whether indeed they were continuous underway measurements. A total of 148015 such measurements were identified and discarded. Given the large volume of this group of data, it is possible that some chlorophyll $a$ observations from in situ methods may have escaped the scrutiny and made it into the final merged dataset. In the future, the SeaBASS plans to add ancillary information to the extractions, which will enable users to distinguish the different types of chlorophyll measurements. The compiled variables from SeaBASS data were: rrs, chla_hplc, chla_fluor, aph, adg, bbp and kd. No conversion was necessary since all variables were acquired in the desired format.

\subsubsection{NASA bio-Optical Marine Algorithm Data set (NOMAD)}

The NASA bio-Optical Marine Algorithm Data set (NOMAD) is a publicly available dataset compiled by the NASA OBPG at the Goddard Space Flight Center. It is a highquality global dataset of coincident radiometric and phytoplankton pigment observations for use in ocean-colour algorithm development and satellite-data product-validation activities (Werdell and Bailey, 2005). The source bio-optical data are the SeaBASS archive; therefore, many dependencies exist between these two datasets, which were addressed during the merging. The current version (Version 2.0 ALPHA, 2008) includes data from 1991 to 2007 and an additional set of observations of inherent optical properties. The current version was used in this work, but with an additional set of columns of remote-sensing reflectance corrected for the bidirectional effects (Morel and Gentili, 1996; Morel et al., 2002). This additional set of columns was provided directly 
by the NOMAD creators. The compiled variables were rrs, chla_hplc, chla_fluor, aph, adg, bbp and kd. Conversion was only necessary for aph, adg and bbp and followed the procedures described in Sect. 2.1. For the calculation of bbp the variable bb was used with a smooth fitting to remove noise. A portion of the NOMAD data were optically weighted (for methods, see Werdell and Bailey, 2005). These data are not consistent with the protocols chosen in this work, but these observations were retained since NOMAD is a widely used dataset in ocean-colour validation.

\subsubsection{MERIS Match-up In situ Database (MERMAID)}

The MERIS Match-up In situ Database (MERMAID) provides in situ bio-optical data matched with concurrent and comparable MERIS Level 2 satellite ocean-colour products (Barker, 2013a, b). The MERMAID in situ database consists of data from multiple contributors, measured using a variety of instruments and protocols, from several marine platforms such as fixed buoys, hand-held radiometers and profiling instruments. Comprehensive quality control and protocols are used by MERMAID to integrate all the data into a common and comparable format (Barker, 2013a, b). Access to MERMAID data is limited to the MERIS Validation Team, the MERIS Quality Working Group and to the in situ data contributors. For this work, access has been granted to the MERMAID database through a signed service-level agreement. The MERMAID data include subsets of several datasets used in this compilation (MOBY, AERONETOC, BOUSSOLE, NOMAD). These observations were removed from the MERMAID dataset to avoid duplication (as discussed in Sect. 2.1). The compiled variables were rrs, chla_hplc, chla_fluor, aph, adg, bbp and kd. Remote-sensing reflectance was calculated by dividing by $\pi$ the original irradiance reflectance provided. Conversion was also necessary for aph, adg and bbp and followed the procedures described in Sect. 2.1.

\subsubsection{Hawaii Ocean Time-series (HOT)}

The Hawaii Ocean Time-series (HOT) programme provides repeated comprehensive observations of the hydrography, chemistry and biology of the water column at a station located $100 \mathrm{~km}$ north of O'ahu, Hawai'i, from October 1988 onwards (Karl and Michaels, 1996). This site is representative of the North Pacific subtropical gyre. Cruises are made approximately once a month to the deep-water station ALOHA (A Long-Term Oligotrophic Habitat Assessment; $22^{\circ} 45^{\prime} \mathrm{N}, 158^{\circ} 00^{\prime} \mathrm{W}$ ). Pigment data (chla_hplc and chla_fluor) were extracted directly from the project website. Radiometric measurements from the HOT project are also available, but observations of rrs and kd from the HOT project were acquired in this work as part of the SeaBASS dataset.

\subsubsection{Geochemistry, Phytoplankton, and Color of the Ocean (GeP\&CO)}

The Geochemistry, Phytoplankton, and Color of the Ocean (GeP\&CO) is part of the French PROcessus Océaniques et Flux (PROOF) programme and aims to describe and understand the variability of phytoplankton populations and to assess its consequences for the geochemistry of the oceans (Dandonneau and Niang, 2007). It is based on the quarterly travels of the merchant ship Contship London from France to New Caledonia. A scientific observer embarked on each travel and operated the sampling for surface water, filtration and various measurements at several hours of each day. The experiment started in October 1999 and finished in July 2002. Pigment data were extracted from the project website. The compiled variable was chla_hplc.

\subsubsection{Atlantic Meridional Transect (AMT)}

The Atlantic Meridional Transect (AMT) is a multidisciplinary programme, which undertakes biological, chemical and physical oceanographic research during an annual voyage between the UK and destinations in the South Atlantic (Robinson et al., 2006). The programme was established in 1995 and since then has completed 23 research cruises. Pigment data between 1997 (AMT5) and 2005 (AMT17) were provided by the British Oceanographic Data Centre (BODC) following a specific request. For any interest in the original data, the BODC is the point of contact, which ensures that if there are any updates, the most recent data are supplied. The compiled variables are chla_hplc and chla_fluor.

\subsubsection{International Council for the Exploration of the Sea (ICES)}

The International Council for the Exploration of the Sea (ICES) is a network of more than 4000 scientists from almost 300 institutes, with 1600 scientists participating in activities annually. The ICES Data Centre manages a number of large dataset collections related to the marine environment covering the North East Atlantic, Baltic Sea, Greenland Sea and Norwegian Sea. The majority of data originate from national institutes that are part of the ICES network of member countries. Data were provided (on 28 April 2014) from the ICES database on the marine environment (Copenhagen, Denmark) following a specific request. The ICES data were made available under the ICES data policy and if there is any conflict between this and the policy adopted by the users, then the ICES policy applies. The compiled variables were chla_hplc and chla_fluor.

\section{Results}

In this work several sets of bio-optical in situ data were acquired, homogenised and merged into a single table. The 
table is comprised of in situ observations between 1997 and 2012, with a global distribution, and include the following variables: remote-sensing reflectance (rrs), chlorophyll $a$ concentration (chla), algal pigment absorption coefficient (aph), detrital and coloured dissolved organic matter absorption (adg), particle backscattering coefficient (bbp), and diffuse attenuation coefficient for downward irradiance (kd). All observations in the table were processed in such a way that they can be compared directly with satellite-derived ocean-colour data. The table consists of 80524 rows and 267 columns. Each row represents a unique station in space and time, separated from each other by at least $5 \mathrm{~min}$ and $200 \mathrm{~m}$. For each observation in a given station, there are three metadata strings: dataset, subdataset and pi. The columns of the table take the form described in Table 1. The contributors of data in the table are shown in Table 2. Regarding spectral variables, all original wavelengths were preserved, which requires a large number of unique wavelengths to be maintained in the database. No band shifting was performed (though some archived data in SeaBASS and MERMAID may have been merged with nearby wavelengths) and no minimum number of wavelengths per observation was imposed. This allows further manipulation of the table for different purposes. In the following paragraphs, the table is analysed and the final group of observations is described for each contributing dataset; however, the numbers reported here do not reflect the original numbers in each dataset, since duplicates across contributing datasets were removed (e.g. removed NOMAD and others from MERMAID).

Observations of remote-sensing reflectance are available at 134 unique wavelengths (i.e. columns), between 405 and $1022.1 \mathrm{~nm}$ (Fig. 1). In total there are 44191 observations (i.e. rows) with remote-sensing reflectance in the table. The total number of observations are partitioned per contributing datasets as follows: AERONET-OC (17405), BOUSSOLE (17364), MOBY (4513), NOMAD (3326), MERMAID (885) and SEABASS (698). The data from AERONET-OC, BOUSSOLE and MOBY correspond to continuous time series and hence the higher number of observations. The data distribution at $44 X \mathrm{~nm}$ and $55 X \mathrm{~nm}$ is provided in Fig. 2a and $b$, respectively. Data were first searched at 445 and $555 \mathrm{~nm}$ and then with a search window of up to $8 \mathrm{~nm}$ to also include data at $547 \mathrm{~nm}$. Median values at $44 X \mathrm{~nm}$ range from $0.003 \mathrm{~m}^{-1}$ (AERONET-OC) and $0.009 \mathrm{~m}^{-1}$ (MOBY), whereas at $55 \mathrm{X} \mathrm{nm}$ the median values lie between $0.001 \mathrm{~m}^{-1}$ (MOBY) and $0.004 \mathrm{~m}^{-1}$ (AERONET-OC). The observations are evenly distributed on a monthly basis in the Northern Hemisphere (Fig. 3). In the Southern Hemisphere, where the number of stations is smaller, there is a decrease in the number of observations during the austral winter months (Fig. 3). For additional analysis, rrs band ratios were plotted against each other (490:555 vs. 412:443, Fig. 4). Most points are within the boundaries of the NOMAD dataset, but some scattered points were found. These points were retained in the table to allow further manipulation with different quality con-
Table 1. The standard variables, nomenclatures and units in the final table.

\begin{tabular}{|c|c|}
\hline Variable/column & Description and units \\
\hline time & GMT, <YYYY-MM-DD>T<HH:MM:SS>Z \\
\hline lat & Decimal degree, $-90: 90$, south negative \\
\hline lon & Decimal degree, $-180: 180$, west negative \\
\hline depth_water & Sampling depth (m) - all assigned to zero \\
\hline chla_hplc & $\begin{array}{l}\text { Total chlorophyll } a \text { concentration determined } \\
\text { from HPLC method }\left(\mathrm{mg} \mathrm{m}^{-3}\right)\end{array}$ \\
\hline chla_fluor & $\begin{array}{l}\text { Chlorophyll } a \text { concentration determined from } \\
\text { fluorometric or spectrophotometric methods } \\
\left(\mathrm{mg} \mathrm{m}^{-3}\right)\end{array}$ \\
\hline rrs_<band $>$ & Remote-sensing reflectance $\left(\mathrm{sr}^{-1}\right)$ \\
\hline aph_<band $>$ & Algal pigment absorption coefficient $\left(\mathrm{m}^{-1}\right)$ \\
\hline adg_<band $>$ & $\begin{array}{l}\text { Detrital plus CDOM absorption coefficient } \\
\left(\mathrm{m}^{-1}\right)\end{array}$ \\
\hline bbp_<band $>$ & Particle backscattering coefficient $\left(\mathrm{m}^{-1}\right)$ \\
\hline kd_<band $>$ & $\begin{array}{l}\text { Diffuse attenuation coefficient for downward } \\
\text { irradiance }\left(\mathrm{m}^{-1}\right)\end{array}$ \\
\hline etopo1 & Water depth from ETOPO1 (m) \\
\hline chla_hplc_dataset & Metadata string for chla_hplc \\
\hline chla_hplc_subdataset & Metadata string for chla_hplc \\
\hline chla_hplc_pi & Metadata string for chla_hplc \\
\hline chla_fluor_dataset & Metadata string for chla_fluor \\
\hline chla_fluor_subdataset & Metadata string for chla_fluor \\
\hline chla_fluor_pi & Metadata string for chla_fluor \\
\hline rrs_dataset & Metadata string for rrs \\
\hline rrs_subdataset & Metadata string for rrs \\
\hline rrs_pi & Metadata string for rrs \\
\hline aph_dataset & Metadata string for aph \\
\hline aph_subdataset & Metadata string for aph \\
\hline aph_pi & Metadata string for aph \\
\hline adg_dataset & Metadata string for adg \\
\hline adg_subdataset & Metadata string for adg \\
\hline adg_pi & Metadata string for adg \\
\hline bbp_dataset & Metadata string for bbp \\
\hline bbp_subdataset & Metadata string for bbp \\
\hline bbp_pi & Metadata string for bbp \\
\hline kd_dataset & Metadata string for $\mathrm{kd}$ \\
\hline kd_subdataset & Metadata string for $\mathrm{kd}$ \\
\hline kd_pi & Metadata string for $\mathrm{kd}$ \\
\hline
\end{tabular}

trol criteria. Complementary analysis of remote-sensing reflectance data is made when other variables are concurrently available and discussed further on in the text (see Figs. 11 and 16). The geographic distribution of remote-sensing reflectance observations (Fig. 5) shows a higher number of observations in some coastal regions, such as those of North America and Northern Europe. The central regions of the ocean show a lower number of observations, with the Atlantic Ocean having the highest density in relation to the other oceans. Best geographic coverage is provided by the NOMAD database. Data from SeaBASS are smaller in number but are still important. Data from MERMAID are mainly located along the coasts of Europe, North America and the central region of the North Atlantic Ocean.

For chlorophyll $a$ concentration, two types of observations were compiled, one measured by fluorometric or spectrophotometric methods (chla_fluor), and the other measured 
Table 2. Original sets of data and data contributors in the final table.

\begin{tabular}{lll}
\hline Data source & Description & Data contributors \\
\hline Marine Optical Buoy & Daily observations of remote-sensing reflectance, measured by & Paul DiGiacomo, Kenneth Voss \\
(MOBY) & a fixed mooring system, located west of the Hawaiian island of & \\
& Lāna'i. Data compiled between 1997-2012. Data were obtained & \\
& from the MOBY website. Compiled standard variable: rrs. &
\end{tabular}

BOUée pour l'acquiSition de Séries Optiques à Long termE (BOUSSOLE)

High frequency (15 min) observations of remote-sensing reflectance, from a fixed mooring system, located in the western Mediterranean Sea. Measurements of chlorophyll $a$ concentration are also available at the mooring locations. Remote-sensing reflectance and chlorophyll $a$ data were compiled between 2003-2012 and 2001-2012, respectively. Data were provided by David Antoine. Compiled standard variables: rrs, chla_hplc.

AErosol RObotic NETwork-Ocean Color (AERONET-OC)

Daily observations of remote-sensing reflectance, measured by modified sun photometers. Data compiled between 2002 2012. Sites included: Abu_Al_Bukhoosh $\left(\sim 25^{\circ} \mathrm{N}, \sim 53^{\circ} \mathrm{E}\right)$, $\left.\sim 29^{\circ} \mathrm{E}\right)$, Gustav Dalen Tower $\left(\sim 58^{\circ} \mathrm{N}, \sim 17^{\circ} \mathrm{E}\right)$, Helsink Lighthouse $\left(\sim 59^{\circ} \mathrm{N}, \sim 24^{\circ} \mathrm{E}\right)$, LISCO $\left(\sim 40^{\circ} \mathrm{N}, \sim 73^{\circ} \mathrm{W}\right)$, Lucinda $\left(\sim 18^{\circ} \mathrm{S}, \sim 146^{\circ} \mathrm{E}\right)$, MVCO $\left(\sim 41^{\circ} \mathrm{N}, \sim 70^{\circ} \mathrm{W}\right)$, Palgrunden $\left(\sim 58^{\circ} \mathrm{N}, \sim 13^{\circ} \mathrm{E}\right)$, Venice $\left(\sim 45^{\circ} \mathrm{N}, \sim 12^{\circ} \mathrm{E}\right)$ and WaveCIS_Site_CSI_6 $\left(\sim 28^{\circ} \mathrm{N}, \sim 90^{\circ} \mathrm{W}\right)$. Data were obtained from the AERONET-OC website. Compiled standard variable: rrs

SeaWiFS Bio-optical Archive and Storage System (SeaBASS)

Global archive of in situ marine data from multiple contributors. Bio-optical global data between 1997-2012 were extracted from the SeaBASS website. Pigment data were extracted using the Data Search tool, which provides data directly from the archives. Radiometric data were extracted using the Validation tool, which only provides in situ data with matchups for oceancolour sensors. Compiled standard variables: rrs, chla_hplc, chl_fluor, aph, adg, bbp and kd. COVE_SEAPRISM $\left(\sim 36^{\circ} \mathrm{N}, \sim 75^{\circ} \mathrm{W}\right)$, Gloria $\left(\sim 44^{\circ} \mathrm{N}\right.$,

David Antoine

Robert Arnone (WaveCIS), Sam Ahmed (LISCO), Vittorio Brando (Lucinda), Dick Crout (WaveCIS), Hui Feng (MVCO), Alex Gilerson (LISCO), Rick Gould (WaveCIS), Brent Holben (COVE-SEAPRISM), Susanne Kratzer (Palgruden), Heidi M. Sosik (MVCO), Giuseppe Zibordi (Abu Al Bukhoosh \& Gloria \& Gustav Dalen Tower \& Helsinki Lighthouse \& Venice)

Robert Arnone, Kevin Arrigo, William Balch, Ray Barlow, Mike Behrenfeld, Şükrü Beşiktepe, Emmanuel Boss, Chris Brown, Douglas Capone, Ken Carder, Francisco Chavez, Alex Chekalyuk, Jay-Chung Chen, Dennis Clark, Hervé Claustre, Jorge Corredor, Glenn Cota, Yves Dandonneau, Heidi Dierssen, David Eslinger, Piotr Flatau, Robert Frouin, Carlos García, Joaquim Goes, Gwo-Ching Gong, Rick Gould, Larry Harding, Jon Hare, Stan Hooker, Chuanmin Hu, Sung-Ho Kang, Gary Kirkpatrick, Oleg Kopelevich, Sam Laney, Zhongping Lee, Ricardo Letelier, Marlon Lewis, Antonio Mannino, John Marra, Chuck McClain, Christophe Menkes, Mark Miller, Greg Mitchell, Ru Morrison, James Mueller, Frank Muller-Karger, James Nelson, Norman Nelson, Mary Jane Perry, David Phinney, John Porter, Collin Roesler, David Siegel, Mike Sieracki, Jeffrey Smart, Raymond Smith, Heidi M. Sosik, James Spinhirne, Dariusz Stramski, Rick Stumpf, Ajit Subramaniam, Chuck Trees, Michael Twardowski, Kenneth Voss, Marcel Wernand, Ronald Zaneveld, Eric Zettler, Giuseppe Zibordi, Richard Zimmerman

Robert Arnone, Kevin Arrigo, William Balch, Ray Barlow, Mike Behrenfeld, Chris Brown, Douglas Capone, Ken Carder, Francisco Chavez, Dennis Clark, Hervé Claustre, Jorge Corredor, Glenn Cota, David Eslinger, Piotr Flatau, Robert Frouin, Rick Gould, Larry Harding, Stan Hooker, Oleg Kopelevich, Marlon Lewis, Antonio Mannino, John Marra, Mark Miller, Greg Mitchell, Tiffany Moisan, Ru Morrison, Frank MullerKarger, James Nelson, Norman Nelson, David Siegel, Raymond Smith, Timothy Smyth, James Spinhirne, Dariusz Stramski, Rick Stumpf, Ajit Subramaniam, Kenneth Voss

Simon Bélanger, Jean-François Berthon, Vanda Brotas, Elisabetta Canuti, Pierre Yves Deschamps, Annelies Hommersom, Mati Kahru, Holger Klein, Hubert Loisel, David McKee, Greg Mitchell, Michael Ondrusek, Michel Repecaud, David Siegel, Giuseppe Zibordi between 2002 and 2012. Access was granted through signed Service Level Agreement. Compiled standard variables: rrs, chla_hplc, chl_fluor, aph, adg, bbp and kd.

$\begin{array}{ll}\text { Atlantic Meridional } & \text { Multidisciplinary programme that makes biological, chemical } \\ \text { Transect (AMT) } & \text { and physical oceanographic measurements during an annual } \\ \text { voyage between the United Kingdom and destinations in the } & \text { South Atlantic. It has compiled observations of chlorophyll } a \\ & \text { concentration between } 1997 \text { (AMT5) and 2005 (AMT17). } \\ & \text { Data were provided by the British Oceanographic Data Centre } \\ & \text { (BODC). Compiled standard variables: chla_hplc, chl_fluor. }\end{array}$

Ray Barlow, Stuart Gibb, Victoria Hill, Patrick Holligan, Gerald Moore, Leonie O'Dowd, Alex Poulton, Emilio Suarez 
Table 2. Continued.

\begin{tabular}{lll}
\hline $\begin{array}{l}\text { International Council for } \\
\text { the Exploration of the Sea } \\
\text { (ICES) }\end{array}$ & $\begin{array}{l}\text { Database of several collections of data related to the marine en- } \\
\text { vironment. It has compiled observations of chlorophyll } a \text { con- } \\
\text { centration in the northern European seas, between 1997 and } \\
\text { 2012. Data were provided by the ICES database on the marine } \\
\text { environment (2014, Copenhagen, Denmark). Compiled stan- } \\
\text { dard variables: chla_hplc, chl_fluor. }\end{array}$ \\
\hline $\begin{array}{l}\text { Hawaii Ocean Time-series } \\
\text { (HOT) }\end{array}$ & $\begin{array}{l}\text { Multidisciplinary programme that makes repeated biological, } \\
\text { chemical and physical oceanographic observations near O'ahu, Bidigare, Matthew Church, Ricardo Letelier, Jasmine } \\
\text { Hawai'i. Measurements of chlorophyll } a \text { concentration between }\end{array}$ \\
& $\begin{array}{l}\text { 1997-2012 were extracted from the project website. Compiled } \\
\text { standard variables: chla_hplc, chl_fluor. }\end{array}$ \\
\hline $\begin{array}{l}\text { Geochemistry, Phytoplank- } \\
\text { ton, and Color of the Ocean } \\
\text { (GeP\&CO) }\end{array}$ & $\begin{array}{l}\text { Program of in situ data collection aboard merchant ship from } \\
\text { France to New Caledonia, between 1999 and 2002. Measure- }\end{array}$ \\
& $\begin{array}{l}\text { ments of chlorophyll } a \text { concentration were obtained from the } \\
\text { project website. Compiled standard variables: chla_hplc. }\end{array}$ \\
\hline
\end{tabular}

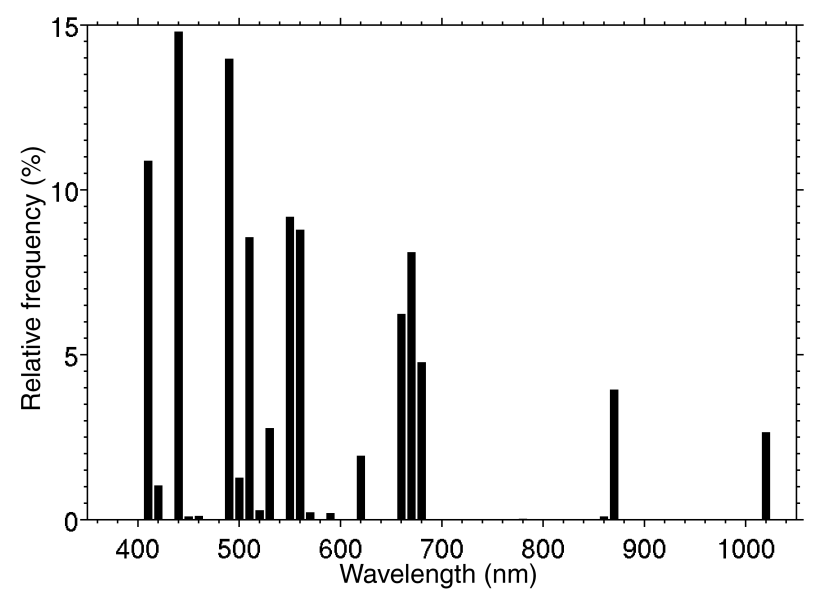

Figure 1. Relative spectral frequency of remote-sensing reflectance in the final table, using $10 \mathrm{~nm}$ wide class intervals, defined as the ratio of the number of observations at a particular waveband to the total number of observations at all wavebands, multiplied by 100 to report results in percentage. Data at a total of 134 unique wavelengths, between 405 and $1022.1 \mathrm{~nm}$, were compiled.
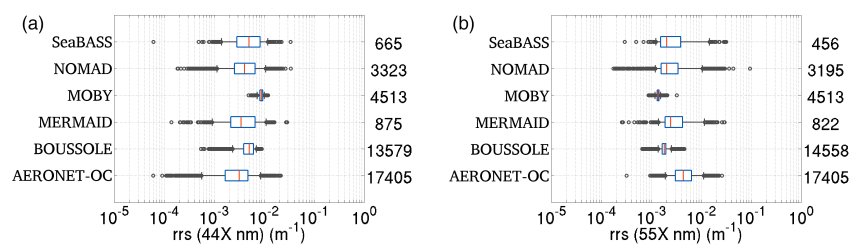

Figure 2. The distribution of (a) $\mathrm{rrs}$ at $44 X \mathrm{~nm}$ and (b) $\mathrm{rrs}$ at $55 X \mathrm{~nm}$. Data were first searched at 445 and $555 \mathrm{~nm}$ and then with a search window of up to $8 \mathrm{~nm}$ to include data at $547 \mathrm{~nm}$. The black boxes delimit the percentiles 0.25 and 0.75 of the data and the black horizontal lines show the extension of up to the 5th and 95th percentiles. The red line represents the median value and the black circles the values below (and above) the percentile 0.05 (0.95). The number of measurements of each dataset is reported on the right axis of the graph.

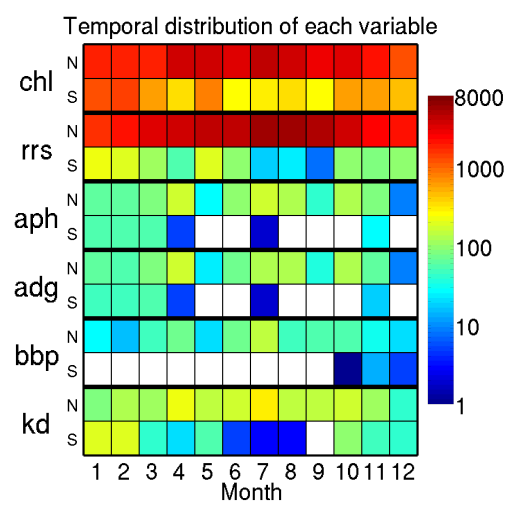

Figure 3. Temporal distribution of chlorophyll $a$ concentration (chl), remote-sensing reflectance (rrs), algal pigment absorption coefficient (aph), detrital plus CDOM absorption coefficient (adg), particle backscattering coefficient (bbp) and the diffuse attenuation coefficient for downward irradiance $(\mathrm{kd})$ in the final table. All chlorophyll data were considered, but for a given station HPLC data were selected if available. Colours indicate the number of stations available for each variable, as a function of months and the hemispheres of data acquisition ( $\mathrm{N}$ - Northern Hemisphere; $\mathrm{S}$ - Southern Hemisphere).

by HPLC methods (chla_hplc). A comparison of both measurements (Fig. 6), when available at the same station shows good agreement (Trees et al., 1985). As stated before, the analysis was done on the final merged table; thus, no data were filtered and the good relation can in part be explained by the quality control implemented by the data providers and curators of repositories such as NOMAD and SeaBASS (Werdell and Bailey, 2005). The total number of rows with concurrent chla_fluor and chla_hplc is 2002, with contributions from NOMAD (32 \%), SeaBASS (47\%), MERMAID (11\%), HOT (7\%), AMT (2\%) and GeP\&CO (1\%). The chla_fluor observations are available at 27933 stations (rows), with values ranging from 0.0011 to $100 \mathrm{mg} \mathrm{m}^{-3}$ (Fig. 7). They are from NOMAD (2350), SeaBASS (15 728), 


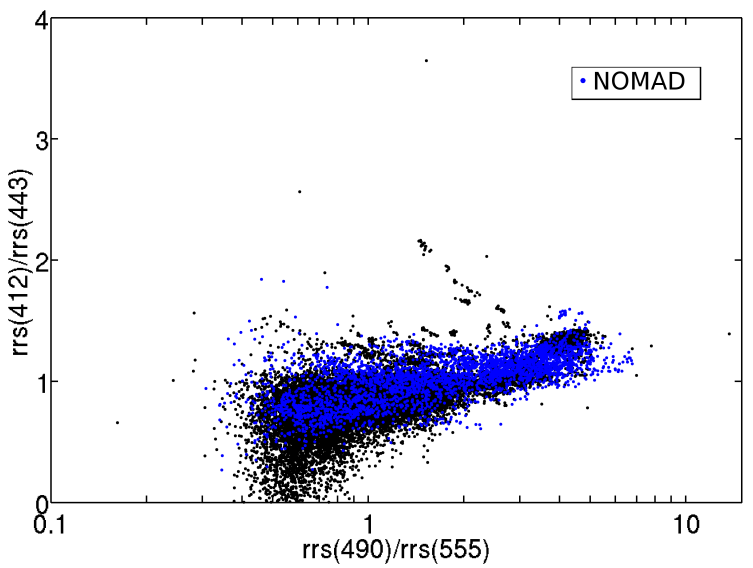

Figure 4. Ranges of remote-sensing reflectance band ratios ( $412: 443$ and $490: 555)$ for all data. The points from the NOMAD dataset are shown in blue for reference. The total number of points is divided between MOBY (4513), AERONET-OC (17 293), BOUSSOLE (3533), NOMAD (3120), SeaBASS (432) and MERMAID (677). To maximise the number of ratios per dataset, a search window of up to $12 \mathrm{~nm}$ was used when the four wavelengths $(412,443$, $490,555)$ were not simultaneously available. The effect of different search windows was negligible in the ratio distribution.

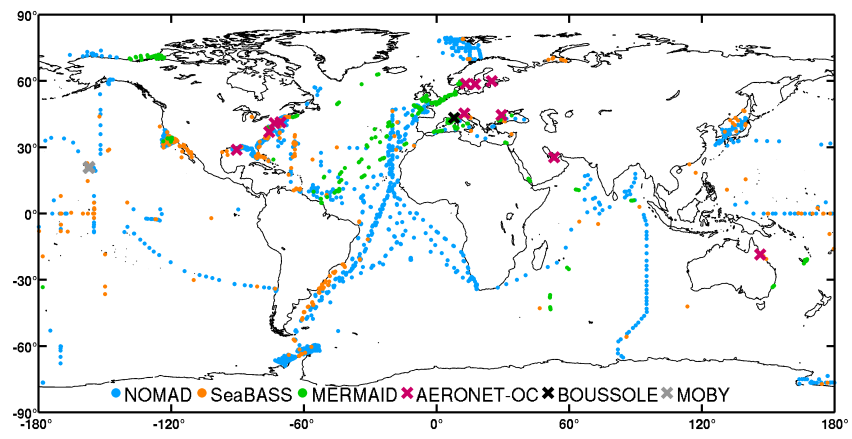

Figure 5. Global distribution of remote-sensing reflectance per dataset in the final table. The data sources are identified with different colours. Points show locations where at least one observation is available. Crosses show sites from where time series data of remote-sensing reflectance are available.

MERMAID (3711), ICES (5421), HOT (559) and AMT (164). The total number of chla_hplc observations is 13918 , ranging from 0.006 to $99.8 \mathrm{mg} \mathrm{m}^{-3}$ (Fig. 7), with contributions from NOMAD (1309), SeaBASS (5920), MERMAID (707), ICES (2994), HOT (153), GeP\&CO (1536), BOUSSOLE (397) and AMT (902). The combined chlorophyll dataset (all chlorophyll data considered, but for a given station HPLC data were selected if available) has a total of 39849 observations, with 11, 41 and $48 \%$ from oligotrophic $\left(<0.1 \mathrm{mg} \mathrm{m}^{-3}\right)$, mesotrophic $\left(0.1-1 \mathrm{mg} \mathrm{m}^{-3}\right)$ and eutrophic $\left(>1 \mathrm{mg} \mathrm{m}^{-3}\right)$ waters, respectively. When compared with the proportions of the world ocean in these trophic classes, i.e. $56 \%$ oligotrophic, $42 \%$ mesotrophic and $2 \%$ eutrophic (An-

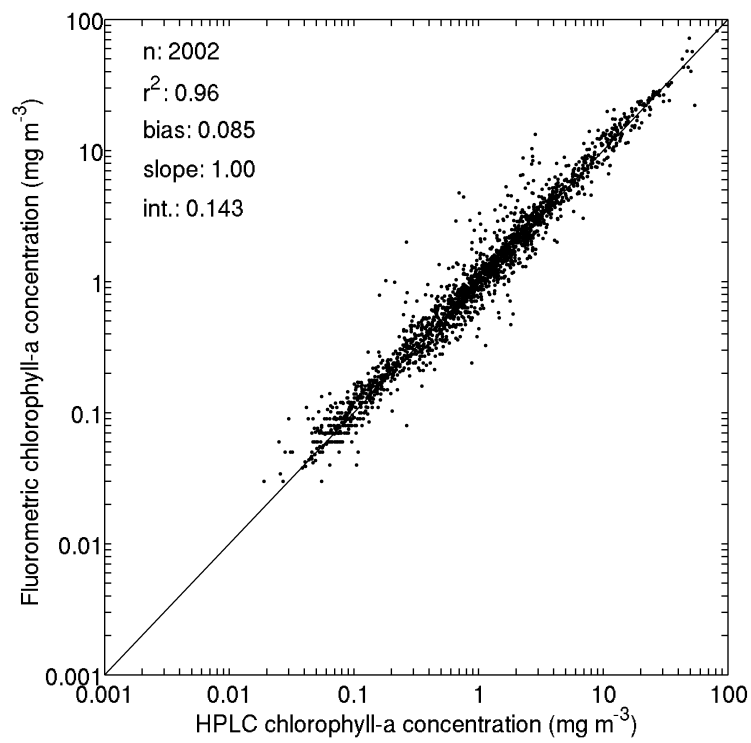

Figure 6. Comparison of coincident observations of chlorophyll $a$ concentration derived with different methods (chla_fluor and chla_hplc). The data were transformed prior to regression analysis to account for their log-normal distribution.

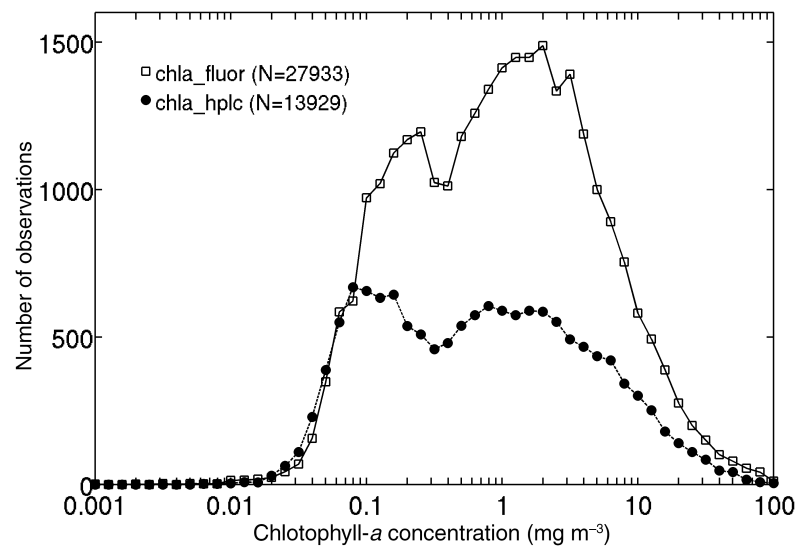

Figure 7. Number of observations per chlorophyll $a$ concentration acquired with different methods ( chla_fluor and chla_hplc).

toine et al., 1996), oligotrophic waters are under-represented and eutrophic waters are over-represented in the compilation. The combined chlorophyll dataset is evenly distributed between each month of the year in the Northern Hemisphere, but in the Southern Hemisphere there are relatively few data points during the winter months compared with the rest of the year (Fig. 3). The spatial distribution of the chlorophyll values for the combined dataset (Fig. 8) shows a good agreement with known biogeographical features, such as low chlorophyll values in the subtropical gyres and high values in temperate, coastal and upwelling regions. Many regions show a good spatial coverage (e.g. Atlantic and Pacific oceans), while others are poorly sampled (e.g. Southern and 


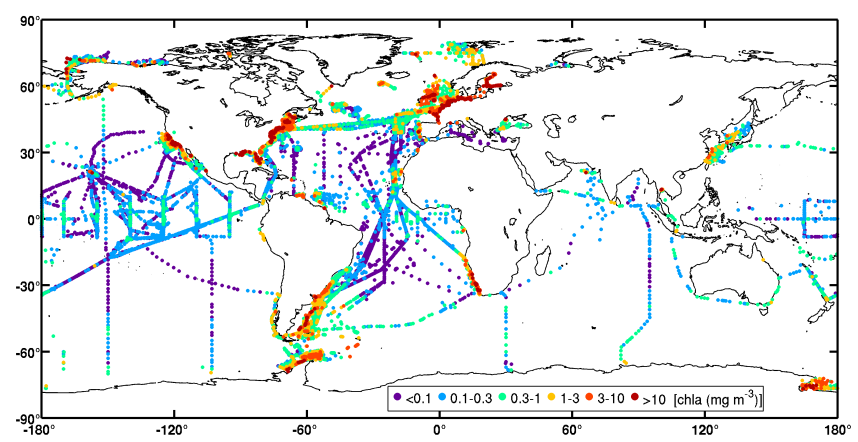

Figure 8. Global distribution of chlorophyll $a$ concentration per intervals of the observed value. All chlorophyll data were considered, but for a given station HPLC data were selected if available.

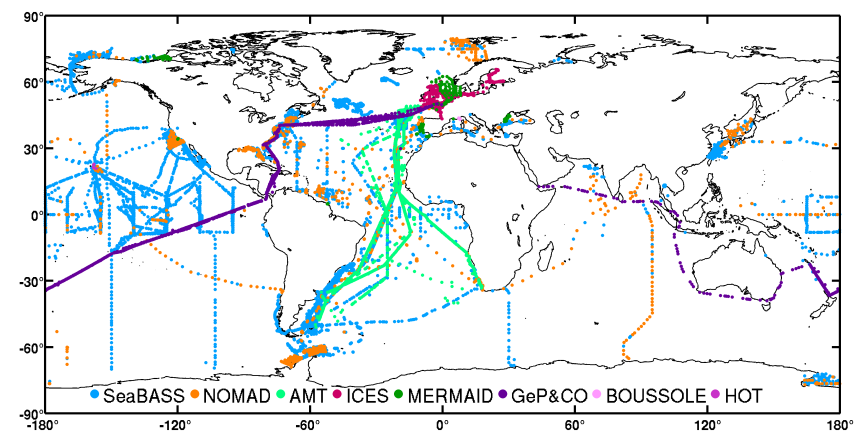

Figure 9. Global distribution of chlorophyll $a$ concentration per dataset in the final table. All chlorophyll data were considered, but for a given station HPLC data were selected if available.

Indian oceans). Of the contributing datasets, NOMAD and SeaBASS provide a good spatial coverage in many regions (Fig. 9). The ICES and MERMAID data are mainly located along the coastal regions of Europe. The AMT data cover the central part of the Atlantic Ocean. For additional analysis and as an example of the applications of the compiled dataset, the combined chlorophyll data (chla_fluor and chla_hplc) were partitioned into $5^{\circ} \times 5^{\circ}$ boxes and for each box the number of observations, average value and standard deviation were computed (Fig. $10 \mathrm{a}, \mathrm{b}$ and c, respectively). The number of observations can be very high $(>1000)$ in some boxes along the European and North American coastlines and relatively low $(<20)$ in oceanic regions. Again there is an appearance in the average value map (Fig. 10b) of well-known biogeographical features, such has the lower chlorophyll in the subtropical gyres and high values in coastal and upwelling areas. There is a close correspondence between the spatial patterns of the averaged and standard deviation maps (Fig. $10 \mathrm{~b}$ and c), which may be an indicator of the data quality.

Coincident observations of chlorophyll $a$ concentration and remote-sensing reflectance are available at 3562 stations. These observations are mostly from NOMAD (85\%), MERMAID $(10 \%)$ and SeaBASS (5\%). The maximum of three band ratios of remote-sensing reflectance is (a)

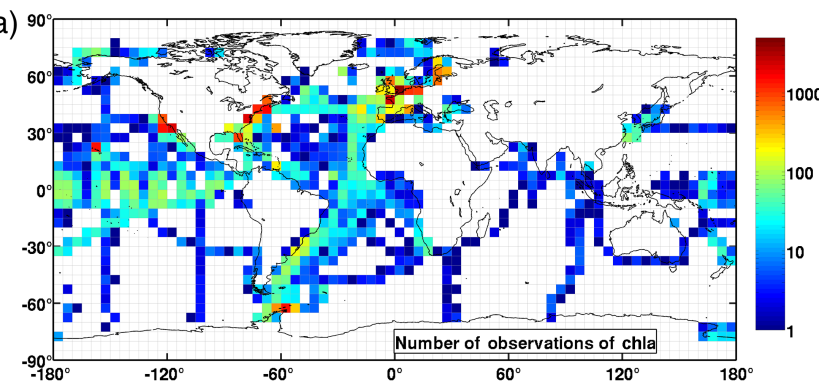

(b)

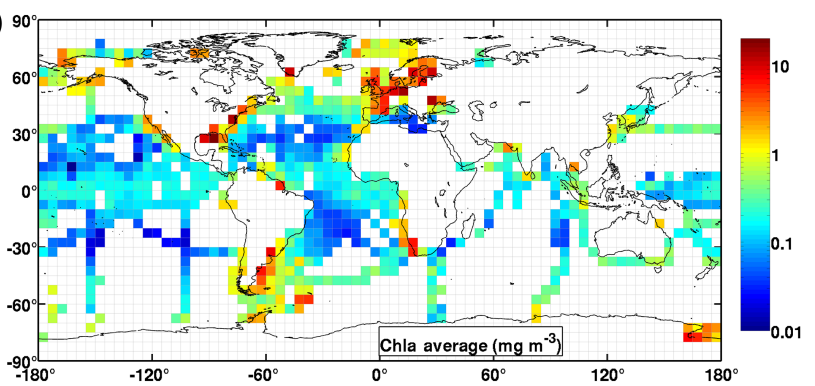

(c)

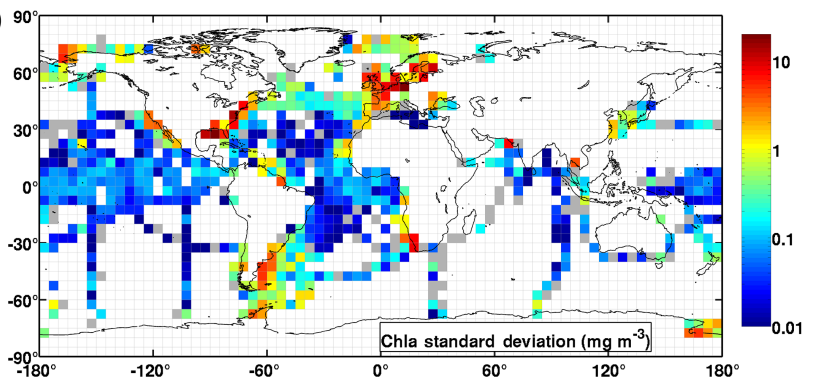

Figure 10. The chlorophyll $a\left(\mathrm{mg} \mathrm{m}^{-3}\right)$ data partitioned into $5^{\circ} \times 5^{\circ}$ boxes showing the (a) number of observations, (b) average value and (c) standard deviation in each box. All chlorophyll data were considered, but for a given station HPLC data were selected if available. In the standard deviation plot, grey represents boxes with zero standard deviation (i.e. one observation).

plotted against chlorophyll $a$ concentration (Fig. 11). The chla values used are the combined HPLC and fluorometric chlorophyll $a$, and for rrs the closest spectral observation within $2 \mathrm{~nm}$ was used. The maximum band ratios were calculated using the maximum value from $[\operatorname{rrs}(443) / \operatorname{rrs}(555), \operatorname{rrs}(490) / \operatorname{rrs}(555), \operatorname{rrs}(510) / \operatorname{rrs}(555)]$ or $\quad[\operatorname{rrs}(443) / \operatorname{rrs}(560), \quad \operatorname{rrs}(490) / \operatorname{rrs}(560)$, $\operatorname{rrs}(510) / \operatorname{rrs}(560)]$ if $\operatorname{rrs}(555)$ was not available. The relationship between maximum band ratio and chlorophyll is close to the NASA OC4 and OC4E v6 standard algorithm (http://oceancolor.gsfc.nasa.gov/cms/atbd/chlor_a), equally based on maximum band ratios, providing confidence in the quality of the compiled data.

The inherent optical properties (aph, adg and bbp) are available at 27 unique wavelengths between 405 and $683 \mathrm{~nm}$. There are a total of 1276, 1123 and 638 observations for aph, adg and bbp, respectively. For aph the total number of observations is distributed among NOMAD (1190), 
Table 3. Summary of median values for aph, adg and bbp at $44 X$ and $55 X \mathrm{~nm}$ for each dataset (as shown in Fig. 12a-f). Data were first searched at 445 and $555 \mathrm{~nm}$ and then with a search window of up to $8 \mathrm{~nm}$ to include data at $547 \mathrm{~nm}$.

\begin{tabular}{lrrrrrrrrr}
\hline & \multicolumn{2}{c}{ Median aph } & & \multicolumn{2}{c}{ Median adg } & & \multicolumn{2}{c}{ Median bbp } \\
\cline { 2 - 3 } \cline { 8 - 9 } & $44 X \mathrm{~nm}$ & $55 X \mathrm{~nm}$ & & $44 X \mathrm{~nm}$ & $55 X \mathrm{~nm}$ & & $44 X \mathrm{~nm}$ & $55 X \mathrm{~nm}$ \\
\hline SeaBASS & 0.0549 & 0.0074 & & 0.0711 & 0.0222 & & 0.0035 & 0.0025 \\
MERMAID & 0.0353 & 0.0046 & & 0.0515 & 0.0112 & & 0.0030 & 0.0022 \\
NOMAD & 0.0282 & 0.0052 & & 0.1149 & 0.0286 & & 0.0080 & 0.0052 \\
\hline
\end{tabular}

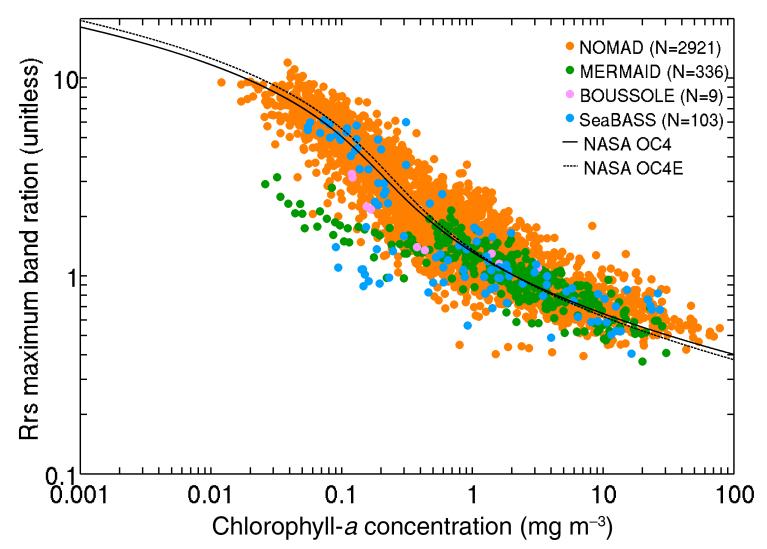

Figure 11. A remote-sensing reflectance maximum band ratio (as defined in text) $([443,490,510] / 555$ or $[443,490,510] / 560$ if 555 not available) as a function of chlorophyll $a$ concentration. All chlorophyll data were considered, but for a given station HPLC data were selected if available. Data within $2 \mathrm{~nm}$ of the wavelengths were used. For reference the solid and dotted line show the NASA OC4 and OC4E v6 standard algorithms, respectively (http://oceancolor.gsfc.nasa.gov/cms/atbd/chlor_a). The total number of points was 3369 , of which $86 \%$ were from NOMAD.

SeaBASS (14) and MERMAID (72). For adg the contributions are as follows: NOMAD (1079), SeaBASS (11) and MERMAID (33). The bbp observations come from NOMAD (371), SeaBASS (32) and MERMAID (235). Data distribution of aph, adg and bbp at $44 X$ and $55 X \mathrm{~nm}$ for each dataset is provided in Fig. 12a-f. Median values of aph, adg and bbp at $44 X$ and $55 X \mathrm{~nm}$ for each dataset are summarised in Table 3. For additional analysis, the following band ratios for the absorption coefficients were calculated: $\operatorname{aph}(490) / \operatorname{aph}(443), \operatorname{aph}(412) / \operatorname{aph}(443)$, $\operatorname{adg}(443) / \operatorname{adg}(490)$ and $\operatorname{adg}(412) / \operatorname{adg}(443)$. Data within $2 \mathrm{~nm}$ of the wavelengths were used to maximise the number of points. The distribution of the ratios is shown in Fig. 13. Several observations were found to be above the thresholds used in the IOCCG report 5 (IOCCG, 2006) for quality control (see dotted vertical black lines in Fig. 13). These points are highlighted here for information but retained in the database, as these were mostly from NOMAD and there was an interest to preserve this dataset as a whole. Also, not discarding this data allows further manipulation with different
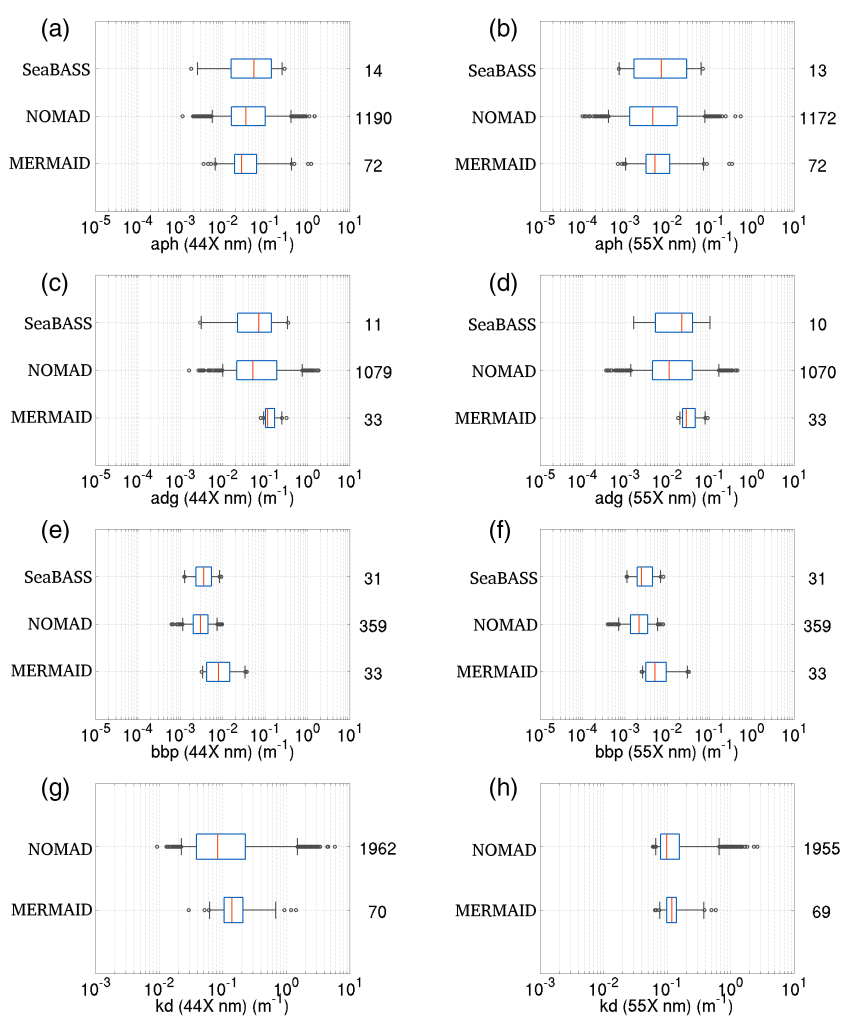

Figure 12. The distribution of (a) aph at $44 X \mathrm{~nm}$, (b) aph at $55 X \mathrm{~nm}$, (c) adg at $44 X \mathrm{~nm}$, (d) adg at $55 X \mathrm{~nm}$, (e) bbp at $44 X \mathrm{~nm}$, (f) bbp at $55 X \mathrm{~nm},(\mathrm{~g}) \mathrm{kd}$ at $44 X \mathrm{~nm}$ and (h) $\mathrm{kd}$ at $55 X \mathrm{~nm}$. Data were first searched at 445 and $555 \mathrm{~nm}$ and then with a search window of up to $8 \mathrm{~nm}$ to include data at $547 \mathrm{~nm}$. The graphical convention is identical to Fig. 2.

quality control criteria. On the annual scale, the observations of the inherent optical properties are strongly underrepresented in the Southern Hemisphere where there is a complete absence of data in several months of the year (Fig. 3). Overall, the geographic coverage for observations of aph, adg and bbp (Fig. 14) is poor, with most open-ocean regions not being sampled, with the exception of the Atlantic Ocean. Small clusters of data are located in particular coastal regions.

Finally, for the diffuse attenuation coefficient for downward irradiance $(\mathrm{kd})$, there are 25 unique wavelengths between 405 and $709 \mathrm{~nm}$. There are a total of 2454 obser- 


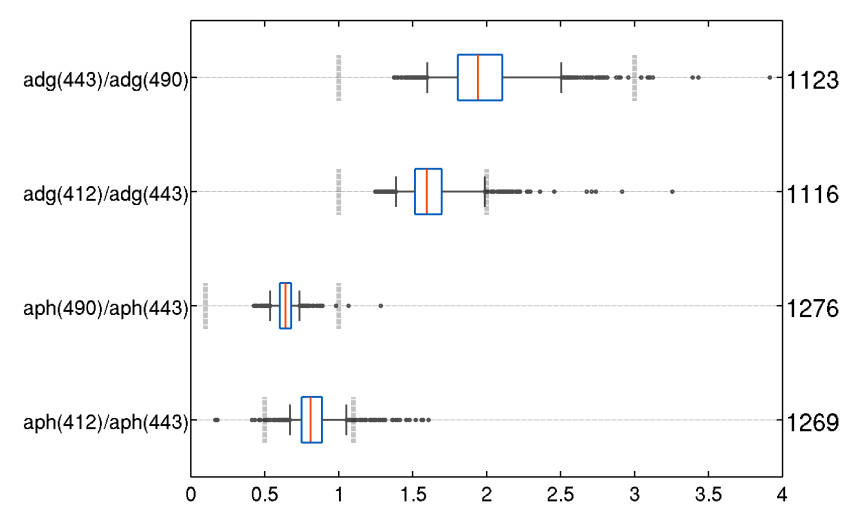

Figure 13. The distribution of absorption coefficient band ratios: $\operatorname{adg}(443) / \operatorname{adg}(490), \operatorname{adg}(412) / \operatorname{adg}(443), \operatorname{aph}(490) / \operatorname{aph}(443)$ and $\operatorname{aph}(412) / \operatorname{aph}(443)$. Data within $2 \mathrm{~nm}$ of the wavelengths were used. The graphical convention is identical to Fig. 2. The vertical dashed lines show the lower and upper thresholds used for quality control in the IOCCG report 5 (IOCCG, 2006). The total number of points are divided between NOMAD (93-96\%), MERMAID (3$6 \%)$ and SeaBASS (1\%).

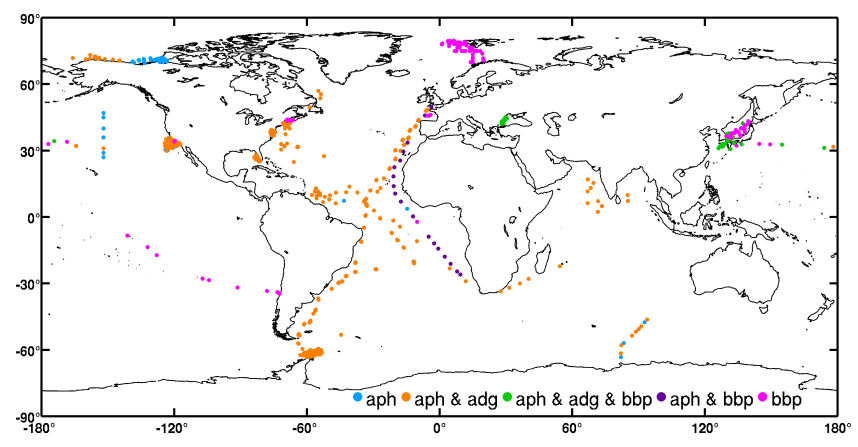

Figure 14. Global distribution of observations of inherent optical properties (algal pigment absorption coefficient aph, detrital plus CDOM absorption coefficient adg and particle backscattering coefficient bbp) in the final table.

vations, from NOMAD (2266), SeaBASS (118) and MERMAID (70). Data distribution of $\mathrm{kd}$ at $44 X$ and $55 X \mathrm{~nm}$ for each dataset is shown in Fig. 12g and h. No kd data at these wavelengths were available for the SeaBASS dataset (only at $490 \mathrm{~nm}$ ). Median values of $\mathrm{kd}$ at $44 X \mathrm{~nm}$ span between $0.08 \mathrm{~m}^{-1}$ (NOMAD) to $0.1 \mathrm{~m}^{-1}$ (MERMAID), whereas at $55 X \mathrm{~nm}$ the kd values are approximately $0.1 \mathrm{~m}^{-1}$ (NOMAD and MERMAID). NOMAD provides the best geographic coverage (Fig. 15), with a higher coverage in the Atlantic, compared with other oceans. With the exception of the coastal regions of North America and the Japan Sea, most coastal regions are not sampled. In the Northern Hemisphere, $\mathrm{kd}$ is distributed roughly evenly across all months of the year, but in the Southern Hemisphere there are few data points during the austral winter and none at all in September (Fig. 3).

Although most of the stations with concurrent variables are mainly from the NOMAD dataset, for complete-

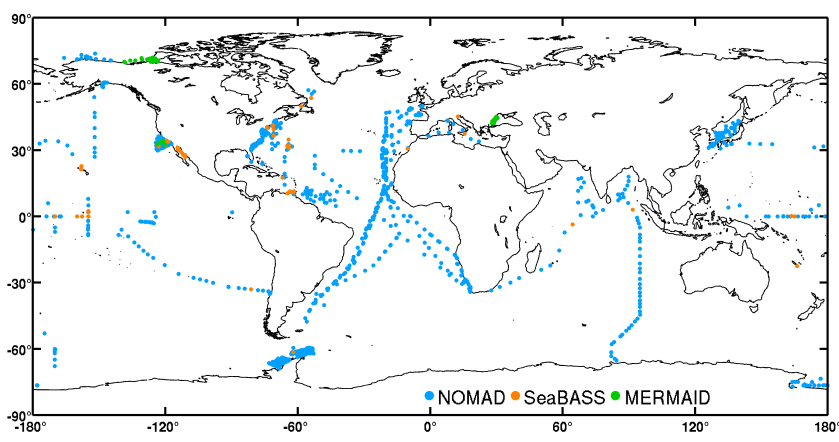

Figure 15. Global distribution of diffuse attenuation coefficient for downward irradiance $(\mathrm{kd})$ per dataset in the final table.

ness, an examination of bio-optical relationships is provided (Fig. 16). The relation between aph at $443 \mathrm{~nm}$ and chlorophyll $a$ (Fig. 16a) agrees with the relation proposed by Bricaud et al. (2004). A total of 1070 points exist with these two variables available (93\% from NOMAD). The relation between the sum of aph and adg at $443 \mathrm{~nm}$ and rrs at $443 \mathrm{~nm}$ (Fig. 16b) shows a similar dispersion, with the exception of some scattered points, to an equivalent analysis on the IOCCG report 5 (see their Fig. 2.3). Again, the scattered data were retained in the final table to preserve the NOMAD dataset. A total of 1112 points exist for which these three variables are available (97\% from NOMAD). The relation between the ratio $\operatorname{rrs}(490) / \operatorname{rrs}(555)$ and $k d(490)$ (Fig. 16c) shows a good agreement with the NASA KD2S standard algorithm (http://oceancolor.gsfc.nasa.gov/cms/atbd/kd_490). A total of 2280 points exist for which these three variables are available (93\% from NOMAD). The relation between the ratio $\operatorname{rrs}(490) / \operatorname{rrs}(555)$ and bbp at $555 \mathrm{~nm}$ (Fig. 16c) shows a good agreement with the relation suggested by Tiwari and Shanmugam (2013). A total of 357 points exist for which these three variables are available (91\% from NOMAD).

\section{Conclusions}

A compilation of bio-optical in situ data is presented in this work. The compiled data have global coverage and span from 1997 to 2012, covering the recent period of ocean-colour satellite observations. They resulted from the acquisition, homogenisation and integration of several sets of data obtained from different sources. Minimal changes were made to the original data, except for those necessary for conversion to standard format and quality control. In situ measurements of the following variables were compiled: remote-sensing reflectance, chlorophyll $a$ concentration, algal pigment absorption coefficient, detrital and coloured dissolved organic matter absorption coefficient, particle backscattering coefficient and diffuse attenuation coefficient for downward irradiance.

The final set of data consists of a substantial number of in situ observations, available in a simple text table, and processed in a way that could be used directly for the evaluation 

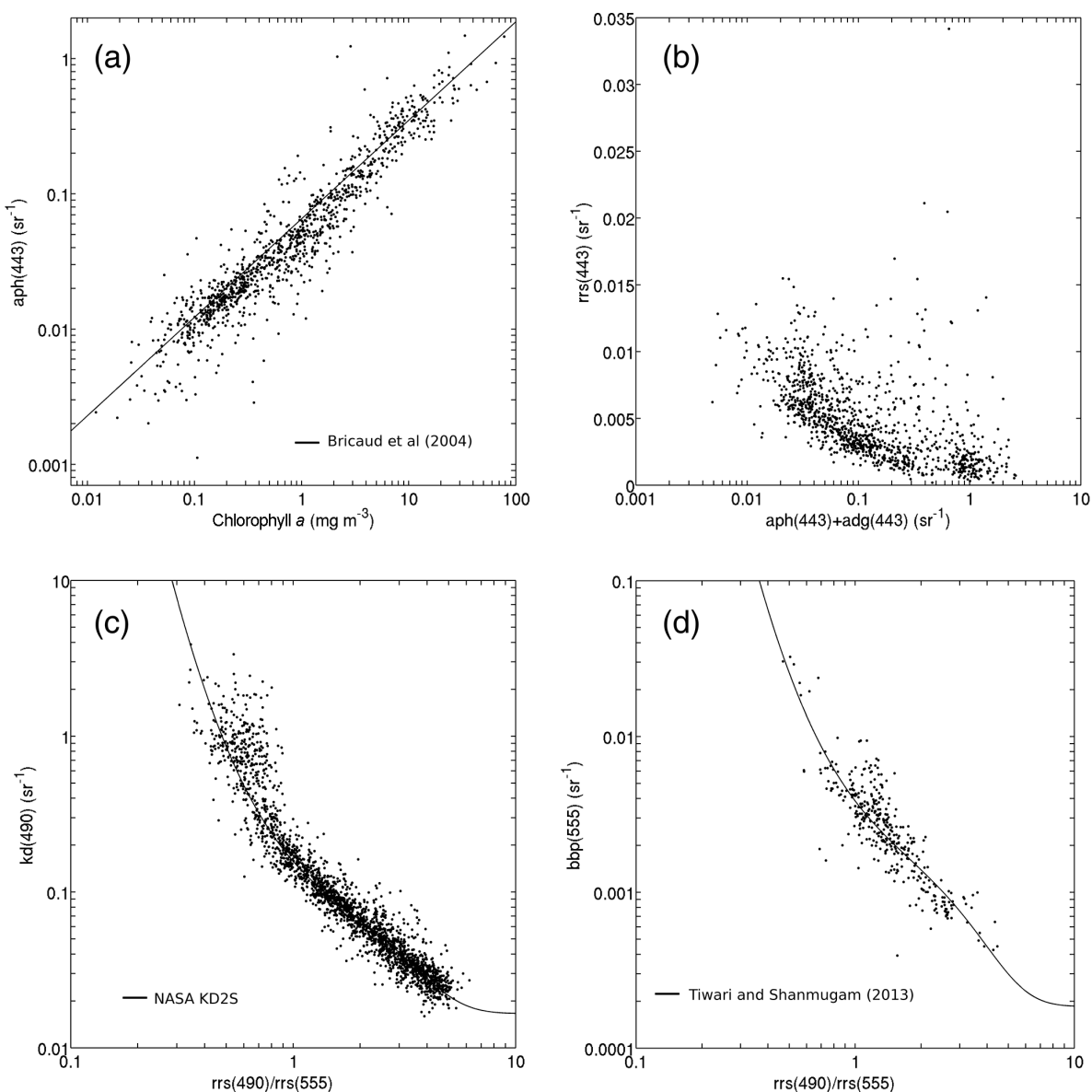

Figure 16. Examples of bio-optical relationships in the final merged table. Panel (a): aph(443) vs. chlorophyll $a$. Total number of points (1070) is divided between MERMAID (70), NOMAD (991) and SeaBASS (9). For reference the solid line show the regression from Bricaud et al. (2004). Panel (b): $[\operatorname{aph}(443)+\operatorname{adg}(443)]$ vs. rrs(443). Total number of points (1112) is divided between MERMAID (33) and NOMAD (1079). Panel (c): [rrs(490) / rrs(555)] vs. kd(490). The total number of points (2280) is divided between MERMAID (62), NOMAD (2117) and SeaBASS (101). For reference the solid line show the NASA KD2S standard algorithm (http://oceancolor.gsfc.nasa.gov/cms/atbd/kd_ 490). Panel (d): $[\operatorname{rrs}(490) / \operatorname{rrs}(555)]$ vs. bbp(555). The total number of points (357) is divided between MERMAID (33) and NOMAD (324). For reference the solid line show the relation proposed by Tiwari and Shanmugam (2013). A search window of $2 \mathrm{~nm}$ was used for panels (a) and (b), and a search window of $5 \mathrm{~nm}$ was used for panels (c) and (d) to include data at $560 \mathrm{~nm}$ when not available at $555 \mathrm{~nm}$.

of satellite-derived ocean-colour data. The major advantages of this compilation are that it merges six commonly used data sources in ocean-colour validation (MOBY, BOUSSOLE, AERONET-OC, SeaBASS, NOMAD, MERMAID) and four additional sets of chlorophyll $a$ concentration data (AMT, ICES, HOT and GeP\&CO) into a simple text table free of duplicated observations. This compilation was initially created with the intention of evaluating the quality of the satellite ocean-colour products from the ESA OC-CCI project. The objective of publishing the compilation is to make it easy for the broader community to use it.

\section{Data availability}

Interested researchers may download the data at https://doi. pangaea.de/10.1594/PANGAEA.854832. For more information on data format see Appendix B. 


\section{Appendix A: Notation}

\begin{tabular}{|c|c|}
\hline $\mathrm{au}$ & Detrital absorption coefficient $\left(\mathrm{m}^{-1}\right)$ \\
\hline $\operatorname{adg}$ & $\begin{array}{l}\text { Detrital plus CDOM absorption coefficient } \\
\left(\mathrm{m}^{-1}\right)\end{array}$ \\
\hline AERONET-OC & AErosol RObotic NETwork-Ocean Color \\
\hline ag & CDOM absorption coefficient $\left(\mathrm{m}^{-1}\right)$ \\
\hline AMT & Atlantic Meridional Transect \\
\hline ap & Particle absorption coefficient $\left(\mathrm{m}^{-1}\right)$ \\
\hline aph & Algal pigment absorption coefficient $\left(\mathrm{m}^{-1}\right)$ \\
\hline aw & Pure water absorption coefficient $\left(\mathrm{m}^{-1}\right)$ \\
\hline $\mathrm{bb}$ & Total backscattering coefficient $\left(\mathrm{m}^{-1}\right)$ \\
\hline bbp & Particle backscattering coefficient $\left(\mathrm{m}^{-1}\right)$ \\
\hline bbw & Backscattering coefficient of seawater $\left(\mathrm{m}^{-1}\right)$ \\
\hline BOUSSOLE & $\begin{array}{l}\text { BOUée pour l'acquiSition de Séries Optiques } \\
\text { à Long termE }\end{array}$ \\
\hline CDOM & Coloured dissolved organic matter \\
\hline chla & Chlorophyll $a$ concentration $\left(\mathrm{mg} \mathrm{m}^{-3}\right)$ \\
\hline chla_fluor & $\begin{array}{l}\text { Chlorophyll } a \text { concentration determined from } \\
\text { fluorometric or spectrophotometric methods } \\
\left(\mathrm{mg} \mathrm{m}^{-3}\right)\end{array}$ \\
\hline chla_hplc & $\begin{array}{l}\text { Total chlorophyll } a \text { concentration determined } \\
\text { from HPLC method }\left(\mathrm{mg} \mathrm{m}^{-3}\right)\end{array}$ \\
\hline Es & $\begin{array}{l}\text { Surface irradiance (or above-water down- } \\
\text { welling irradiance) }\left(\mathrm{mW} \mathrm{cm}^{-2} \mu \mathrm{m}^{-1}\right)\end{array}$ \\
\hline ESA & European Space Agency \\
\hline Fo & $\begin{array}{l}\text { Top-of-the-atmosphere solar irradiance } \\
\left(\mathrm{mW} \mathrm{cm} \mathrm{cm}^{-2} \mu \mathrm{m}^{-1}\right)\end{array}$ \\
\hline $\mathrm{GeP} \& \mathrm{CO}$ & $\begin{array}{l}\text { Geochemistry, Phytoplankton, and Color of } \\
\text { the Ocean }\end{array}$ \\
\hline HOT & Hawaii Ocean Time-series \\
\hline HPLC & High-performance liquid chromatography \\
\hline ICES & $\begin{array}{l}\text { International Council for the Exploration of } \\
\text { the Sea }\end{array}$ \\
\hline $\mathrm{kd}$ & $\begin{array}{l}\text { Diffuse attenuation coefficient for downward } \\
\text { irradiance }\left(\mathrm{m}^{-1}\right)\end{array}$ \\
\hline Lw & $\begin{array}{l}\text { Water-leaving radiance (or above-water } \\
\text { upwelling radiance) }\left(\mathrm{mW} \mathrm{cm} \mathrm{cm}^{-2} \mu \mathrm{m}^{-1} \mathrm{sr}^{-1}\right)\end{array}$ \\
\hline MERIS & Medium Resolution Imaging Spectrometer \\
\hline MERMAID & MERIS Match-up In situ Database \\
\hline MOBY & Marine Optical Buoy \\
\hline MODIS & $\begin{array}{l}\text { Moderate Resolution Imaging Spectro- } \\
\text { radiometer }\end{array}$ \\
\hline NASA & $\begin{array}{l}\text { National Aeronautics and Space } \\
\text { Administration }\end{array}$ \\
\hline $\mathrm{nLw}$ & $\begin{array}{l}\text { Normalised water-leaving radiance } \\
\left(\mathrm{mW} \mathrm{cm} \mathrm{cm}^{-2} \mu \mathrm{m}^{-1} \mathrm{sr}^{-1}\right)\end{array}$ \\
\hline nLw_ex & $\begin{array}{l}\mathrm{nLw} \text { with a correction for bidirectional effects } \\
\left(\mathrm{mW} \mathrm{cm}-2 \mu \mathrm{m}^{-1} \mathrm{sr}^{-1}\right)\end{array}$ \\
\hline NOMAD & NASA bio-Optical Marine Algorithm Data set \\
\hline OC-CCI & Ocean Colour Climate Change Initiative \\
\hline rrs & Remote-sensing reflectance $\left(\mathrm{sr}^{-1}\right)$ \\
\hline SeaBASS & $\begin{array}{l}\text { SeaWiFS Bio-optical Archive and Storage } \\
\text { System }\end{array}$ \\
\hline SeaWiFS & Sea-viewing Wide Field-of-view Sensor \\
\hline $\mathrm{Rw}$ & Irradiance reflectance (dimensionless) \\
\hline
\end{tabular}

\section{Appendix B: Data table}

The compiled data are available at doi:10.1594/PANGAEA.854832. The merged text table described in this work, considered here as the main table, is accompanied by four extra files. One extra file is a csv table with detailed information about the number of observations per variable, dataset, subdataset and pi. Two other extra files are text tables generated from the main table, and are provided to help with the analysis of spectral data. These two files contain the spectral data aggregated within \pm 2 and $\pm 6 \mathrm{~nm}$, respectively, of SeaWiFS, MODIS AQUA and MERIS sensor bands. The files are generated by assigning, in each row of the main table, the closest spectral observation within $2 \mathrm{~nm}$ (or $6 \mathrm{~nm}$ ) of a sensor band. The centre wavelength of each band and sensor used in the generation of the files is the following: SeaWiFS bands 1-8 were centred at $[412,443,490,510,555,670,765,865] \mathrm{nm}$, respectively; MODIS-AQUA bands 1-9 were centred at [412, 443, 488, $531,547,667,678,748,869] \mathrm{nm}$, respectively; and MERIS bands $1-13$ were centred at $[412,442,490,510,560,620$, $665,681,709,753,779,865,885] \mathrm{nm}$, respectively. An exception to this procedure was made to confirm that the correct MOBY data are stored in the files (see Sect. 2.2.1. for discussion on how MOBY wavelengths are stored in the main file). Finally, a readme file is provided to help the user. 
Author contributions. The first six authors belong to the ESA OC-CCI team and contributed to the design of the compilation. The remaining authors are listed alphabetically and are data contributors (see their respective dataset on Table 2) or individuals responsible for the development of a particular dataset (Jeremy Werdell for NOMAD and Katherine Barker for MERMAID). All data contributors (listed on Table 2) were contacted for authorisation of data publishing and offered co-authorship. In the case of the ICES dataset the permission for publishing was given by the ICES team. All the authors have critically reviewed the manuscript.

Acknowledgements. This paper is a contribution to the ESA OC-CCI project. This work is also a contribution to project PEst-OE/MAR/UI0199/2014. We are grateful for the efforts of the teams responsible for the collection of the data in the field and of the teams responsible for processing and storing the data in archives, without which this work would not be possible. We thank Tamoghna Acharyya and Robert Brewin at Plymouth Marine Laboratory for their initial contribution to this work. We thank the NOAA (US) for making available the MOBY data and Yong Sung Kim for the help with questions about MOBY data. BOUSSOLE is supported and funded by the European Space Agency (ESA), the Centre National d'Etudes Spatiales (CNES), the Centre National de la Recherche Scientifique (CNRS), the Institut National des Sciences de l'Univers (INSU), the Université Pierre et Marie Curie (UPMC) and the Observatoire Océanologique de Villefranche-sur-mer (OOV). We thank ACRIST, ARGANS and ESA for access to the MERMAID Database (http://hermes.acri.fr/mermaid). We thank Annelies Hommersom, Pierre Yves Deschamps and David Siegel for allowing the use of MERMAID data for which they are principal investigators. We thank the British Oceanographic Data Centre (BODC) for access to AMT data and in particular Polly Hadziabdic and Rob Thomas for their help with questions about the AMT dataset. We thank Victoria Hill, Patrick Holligan, Gerald Moore and Emilio Suarez for the use of AMT data for which they are principal investigators. We thank Sam Ahmed, Hui Feng, Alex Gilerson and Brent Holben for allowing the use of the AERONET-OC data for which they are principal investigators. We thank also the AERONET staff and site support people. We thank Bob Bidigare, Matthew Church, Ricardo Letelier and Jasmine Nahorniak for making the HOT data available, and the National Science Foundation for support of the HOT research (grant OCE 09-26766). We thank Yves Dandonneau for allowing the use of GeP\&CO data. We thank the ICES database on the marine environment (Copenhagen, Denmark, 2014) for allowing the use of their archived data, and Marilynn Sørensen for the help with questions about the ICES dataset. We thank all ICES contributors for their data. We thank Eric Zettler and the SEA Education Association. We thank NASA, SeaBASS and the Ocean Biology Processing Group (OBPG) for access to SeaBASS and NOMAD data. We thank NASA for project funding for data collection. We thank Chris Proctor from SeaBASS for his valuable and prompt help with a variety of questions. Finally, we are deeply thankful to the data contributors of NOMAD and SeaBASS: Kevin Arrigo, Mike Behrenfeld, Emmanuel Boss, Chris Brown, Douglas Capone, Ken Carder, Alex Chekalyuk, Jay-Chung Chen, Dennis Clark, Jorge Corredor, Glenn Cota, Yves Dandonneau, Heidi Dierssen, David Eslinger, Piotr Flatau, Joaquim Goes,
Gwo-Ching Gong, Larry Harding, Jon Hare, Chuanmin Hu, Sung-Ho Kang, Gary Kirkpatrick, Oleg Kopelevich, Sam Laney, Zhongping Lee, Ricardo Letelier, Marlon Lewis, Antonio Mannino, John Marra, Chuck McClain, Christophe Menkes, Mark Miller, $\mathrm{Ru}$ Morrison, James Mueller, James Nelson, Norman Nelson, Mary Jane Perry, David Phinney, John Porter, Collin Roesler, David Siegel, Mike Sieracki, Jeffrey Smart, Raymond Smith, James Spinhirne, Dariusz Stramski, Rick Stumpf, Ajit Subramaniam, Chuck Trees, Ronald Zaneveld, Eric Zettler and Richard Zimmerman.

Edited by: D. Carlson

\section{References}

Amante, C. and Eakins, B. W.: ETOPO1, 1 Arc-Minute Global Relief Model: Procedures, Data Sources and Analysis, NOAA Technical Memorandum NESDIS NGDC-24. National Geophysical Data Center, NOAA, available at: https://catalog.data. gov/dataset/etopo1-1-arc-minute-global-relief-model/resource/ 9e53be26-60cb-4139-b70c-51a2c4561bbb (last access: 3 June 2016), 2009.

Antoine, D., André, J. M., and Morel, A.: Oceanic primary production: 2. Estimation at global scale from satellite (CZCS) chlorophyll, Global Biogeochem. Cy., 10, 57-70, 1996.

Antoine, D., Chami, M., Claustre, H., D’Ortenzio, F., Morel, A., Bécu, G., Gentili, B., Louis, F., Ras, J., Roussier, E., Scott, A. J., Tailliez, D., Hooker, S. B.,Guevel, P., Desté, J.-F., Dempsey, C., and Adams, D.: BOUSSOLE : a joint CNRS-INSU, ESA, CNES and NASA Ocean Color Calibration And Validation Activity. NASA Technical memorandum No. 2006-214147, 61 pp., available at: http://ntrs.nasa.gov/archive/nasa/casi.ntrs.nasa.gov/ 20070028812.pdf (last access: 3 June 2016), 2006.

Antoine, D., Guevel, P., Desté, J.-F., Bécu, G., Louis, F., Scott, A., and Bardey, P.: The "BOUSSOLE" Buoy - A New Transparentto-Swell Taut Mooring Dedicated to Marine Optics: Design, Tests, and Performance at Sea. J. Atmos. Oceanic Technol., 25, 968-989, 2008.

Bailey, S. W. and Werdell, P. J.: A multi-sensor approach for the on-orbit validation of ocean color satellite data products, Remote Sens. Environ., 102, 12-23, 2006.

Barker, K.: In-situ Measurement Protocols. Part A: Apparent Optical Properties, Issue 2.0, Doc. no: CO-SCIARG-TN-0008, ARGANS Ltd., p. 126, available at: http://mermaid.acri.fr/dataproto/CO-SCI-ARG-TN-0008_ In-situ_Measurement_Protocols-AOPs_Issue2_Mar2013.pdf (last access: 3 June 2016), 2013a.

Barker, K.: In-situ Measurement Protocols. Part B: Inherent Optical Properties and in-water constituents, Issue 1.0, Doc. no: CO-SCI-ARG-TN-0008, ARGANS Ltd., p. 39, available at: http://mermaid.acri.fr/dataproto/CO-SCI-ARG-TN-0008_ In-situ_Measurement_Protocols-IOPs-Constituents_Issue1_ Mar2013.pdf (last access: 3 June 2016), 2013b.

Bricaud, A., Claustre, H., Ras, J., and Oubelkheir, K.: Natural variability of phytoplanktonic absorption in oceanic waters: Influence of the size sctructure of algal populations, J. Geophys. Res., 109, C11010, doi:10.1029/2004JC002419, 2004.

Clark, D. K., Yarborough, M. A., Feinholz, M. E., Flora, S., Broenkow, W., Kim, Y. S., Johnson, B. C., Brown, S. W., Yuen, 
M., and Mueller, J. L.: MOBY, A Radiometric Buoy for Performance Monitoring and Vicarious Calibration of Satellite Ocean Colour Sensors: Measurements and Data Analysis Protocols, in: Ocean Optics Protocols for Satellite Ocean Colour Sensor Validation, edited by: Muller, J. L., Fargion, G., and McClain, C., NASA Technical Memo. 2003-211621/Rev4, Vol. VI, 3-34, NASA/GSFC, Greenbelt, MD, USA, 2003.

Dandonneau, Y. and Niang, A.: Assemblages of phytoplankton pigments along a shipping line through the North Atlantic and Tropical Pacific, Prog. Oceanogr., 73, 127-144, 2007.

Gordon, H. R. and Clark, D. K.: Clear water radiances for atmospheric correction of coastal zone color scanner imagery, Appl. Optics, 20, 4175-4180, 1981.

Gregg, W. W. and Carder, K. L.: A simple spectral solar irradiance model for cloudless maritime atmospheres, Limnol. Oceanogr., 35, 1657-1675, 1990.

IOCCG: Report 5: Remote Sensing of Inherent Optical Properties: Fundamentals, Tests of Algorithms, and Applications, in: Reports of the International Ocean-Colour Coordinating Group, edited by: Lee, Z.-P., No. 5. vol. 5, IOCCG, 2006, Dartmouth, Canada, p. 126, 2006.

IOCCG: Why Ocean Colour? The Societal Benefits of OceanColour Technology, in: Reports of the International OceanColour Coordinating Group, edited by: Platt, T., Hoepffner, N., Stuart, V., and Brown, C., No. 7, IOCCG, Dartmouth, Canada, 2008.

Karl, D. M. and Michaels, A. F.: The Hawaiian Ocean Time-series (HOT) and Bermuda Atlantic Time-series Study (BATS) - Preface, Deep-Sea Res. II, 43, 127-128, 1996.

Morel, A. and Gentilli, B.: Diffuse Reflectance of Oceanic Waters. 3. Implications of Bidirectionality for the Remote-Sensing Problem, Appl. Optics, 35, 4850-4862, 1996.

Morel, A. and Maritorena, S.: Bio-optical properties of oceanic waters: A reappraisal, J. Geophys. Res., 106, 7163-7180, 2001.

Morel, A., Antoine, D., and Gentilli, B.: Bidirectional reflectance of oceanic waters: accounting for Raman emission and varying particle scattering phase function, Appl. Optics, 41, 6289-6306, 2002.

Nechad, B., Ruddick, K., Schroeder, T., Oubelkheir, K., BlondeauPatissier, D., Cherukuru, N., Brando, V., Dekker, A., Clementson, L., Banks, A. C., Maritorena, S., Werdell, P. J., Sá, C., Brotas, V., Caballero de Frutos, I., Ahn, Y.-H., Salama, S., Tilstone, G., Martinez-Vicente, V., Foley, D., McKibben, M., Nahorniak, J., Peterson, T., Siliò-Calzada, A., Röttgers, R., Lee, Z., Peters, M., and Brockmann, C.: CoastColour Round Robin data sets: a database to evaluate the performance of algorithms for the retrieval of water quality parameters in coastal waters, Earth Syst. Sci. Data, 7, 319-348, doi:10.5194/essd-7-319-2015, 2015.

Pope, R. and Fry, E.: Absorption spectrum (380-700 nm) of pure waters: II. Integrating cavity measurements, Appl. Optics, 36, 8710-8723, 1997.
Robinson, C., Poulton, A. J., Holligan, P. M., Baker, A. R., Forster, G., Gist, N., Jickells, T. D., Malin G., Upstill-Goddard, R., Williams, R. G., Woodward, E. M. S., and Zubkov, M. V.: The Atlantic Meridional Transect (AMT) Programme: a contextual view 1995-2005, Deep-Sea Res. II, 53, 1485-1515, doi:10.1016/j.dsr2.2006.05.015, 2006.

Thuillier, G., Hersé, M., Labs, D., Foujols, T., Peetermans, W., Gillotay, D., Simon, P. C., and Mandel, H.: The solar spectral irradiance from $200 \mathrm{nnm}$ to $2400 \mathrm{~nm}$ as measured by the SOLSPEC spectrometer from the ATLAS 1-2-3 and EURECA missions, Sol. Phys., 214, 1-22, 2003.

Tiwari, S. P. and Shanmugam, P.: An optical model for deriving the spectral particulate backscattering coefficients in oceanic waters, Ocean Sci., 9, 987-1001, 2013.

Trees, C. C., Kennicutt II, M. C., and Brooks, J. M.: Errors associated with the standard fluorimetric determination of chlorophylls and phaeopigments, Mar. Chem., 17, 1-12, 1985.

Valente, A., Sathyendranath, S., Brotas, V., Groom, S., Grant, M., Taberner, M., Antoine, D., Arnone, R., Balch, W. M., Barker, K., Barlow, R., Bélanger, S., Berthon, J.-F., Besiktepe, S., Brando, V., Canuti, E., Chavez, F. P., Claustre, H., Crout, R., Frouin, R., García-Soto, C., Gibb, S., Gould, R., Hooker, S., Kahru, M., Klein, H., Kratzer, S., Loisel, H., McKee, D,. Mitchell, G., Moisan, T., Muller-Karger, F. E., O’Dowd, L., Ondrusek, M., Poulton, A. J., Repecaud, M., Smyth, T. J., Sosik, H., Twardowski, M. S., Voss, K., Werdell, P. J., Wernand, M. R., and Zibordi, G.: A compilation of global bio-optical in situ data for ocean-colour satellite applications, doi:10.1594/PANGAEA.854832, 2015.

Werdell, P. J. and Bailey, S. W.: An improved bio-optical data set for ocean color algorithm development and satellite data product validation, Remote Sens. Environ., 98, 122-140, 2005.

Werdell, P. J., Bailey, S., Fargion, G., Pietras, C., Knobelspiesse, K., Feldman, G., and McClain, C.: Unique data repository facilitates ocean color satellite validation, EOS Transactions AGU, 84, 377-387, 2003.

Zhang, X., Hu, L., and He, M.-X.: Scattering by pure seawater: Effect of Salinity, Opt. Express, 17, 5698-5710, 2009.

Zibordi, G., Holben, B. N., Hooker, S. B., Mélin, F., Berthon, J.-F., Slutsker, I., Giles, D., Vandemark, D., Feng, H., Rutledge, K., Schuster, G., and Al Mandoos, A.: A network for standardized ocean color validation measurements, EOS Trans. Am. Geophys. Union, 87, 293-297, 2006.

Zibordi, G., Holben, B. N., Slutsker, I., Giles, D., D’Alimonte, D., Mélin, F., Berthon, J.-F., Vandemark, D., Feng, H., Schuster, G., Fabbri, B. E., Kaitala, S., and Seppälä, J.: AERONET-OC: A network for the validation of ocean color primary radiometric products, J. Atmos. Ocean. Tech., 26, 1634-1651, 2009. 